\title{
Tolerancia religiosa e inmigración. México y Nueva Granada a finales de la década de $1840^{*}$
}

\section{Resumen}

El artículo expone cómo a finales de la década de 1840, a raíz de la propuesta de proyectos de colonización que contemplaban la inmigración de extranjeros, se debatió la tolerancia religiosa en México y Nueva Granada. Planteamos que en esas propuestas de colonización se mostró de manera clara la relación existente entre tolerancia religiosa e inmigración. Esto significa que la primera era una condición fundamental para que se presentara la segunda, con lo cual la tolerancia religiosa adquiría una connotación práctica. Exponemos, analizamos e interpretamos los argumentos, a favor y en contra, con representaciones e imaginarios, que se construyeron sobre la relación tolerancia religiosa e inmigración. Las discusiones por la tolerancia religiosa relacionadas con la inmigración están inmersas en debates más amplios en donde la política y la religión jugaron papel importante en la delineación de formas de ver y vivir el mundo.

\section{Palabras clave}

Tesauro: México, Colombia, tolerancia, intolerancia, inmigración.

Autor: siglo XIX, tolerancia religiosa.

Referencia para citar este artículo: Cortés Guerrero, José David. “Tolerancia religiosa e inmigración. México y Nueva Granada a finales de la década de 1840". Anuario de Historia Regional y de las Fronteras 23.2 (2018): 51-84.

Fecha de recepción: 29/11/2017

Fecha de aceptación: 26/04/2018

José David Cortés Guerrero: doctor en Historia, El Colegio de México, México. Magíster en Historia, El Colegio de México, México. Magíster en Historia, Universidad Nacional de Colombia, Bogotá. Licenciado en Ciencias Sociales, Universidad Pedagógica Nacional, Bogotá. Miembro del Grupo de Investigación Prácticas, Imaginarios y Representaciones, categoría A en Colciencias. Profesor asociado, Departamento de Historia, Universidad Nacional de Colombia, sede Bogotá, Colombia. Código ORCID: https://orcid.org/0000-0002-2581-7442. Correo electrónico: jdcortesg@unal.edu.co.

\footnotetext{
* El artículo es resultado parcial de las siguientes investigaciones "Tolerancia y libertad religiosas en México y Colombia en el siglo XIX”, Universidad Nacional de Colombia-Sede Bogotá, Programa de Trabajo Académico, Código Hermes 37917; y, "Representaciones e imaginarios del protestantismo en México. 1824-1860", beca de excelencia Genaro Estrada para Expertos Mexicanistas, Secretaría de Relaciones Exteriores de México, 2015.
} 


\title{
Religious Tolerance and Immigration. Mexico and Nueva Granada at the end of the 1840s
}

\begin{abstract}
The article shows how in 1840's, following the proposal of colonization projects that contemplated the immigration of foreigners, religious tolerance was debated in Mexico and "Nueva Granada". We argue that these proposals for colonization showed clearly the relationship between religious tolerance and immigration. This means that the religious tolerance was a fundamental condition for the immigration, in which, religious tolerance acquired a practical connotation. We describe, analyze and interpret the arguments, for and against, representations and imaginaries, that were built on the relationship between religious tolerance and immigration. The discussions on religious tolerance related to immigration are immersed in broader debates. In these debates, politics and religion played an important role in creating ways of seeing and living the world.
\end{abstract}

Keywords

Thesaurus: México, Colombia, Tolerance, Intolerance, Immigration.

Author's keywords: 19th Century, Religious Tolerance.

\section{Tolerância religiosa e imigração. México e Nova Granada no final da década de 1840}

\section{Resumo}

O artigo expõe como no final da década de 1840, seguindo a proposta de projetos de colonização que contemplavam a imigração de estrangeiros, foi debatida a tolerância religiosa no México e em Nova Granada. Propomos que nestas propostas de colonização a relação entre tolerância religiosa e imigração foi claramente mostrada. Isso significa que a primeira foi uma condição fundamental para a segunda, com a qual a tolerância religiosa adquiriu uma conotação prática. Nós expomos, analisamos e interpretamos os argumentos a favor e contra, com representações e imaginários, que foram construídos sobre a relação entre tolerância religiosa e imigração. As discussões sobre a tolerância religiosa relacionadas à imigração estão imersas em debates mais amplos, nos quais a política e a religião tiveram um papel importante no delineamento de modos de ver e viver o mundo.

\section{Palavras-chave}

Thesaurus: México, Colômbia, tolerância, intolerância, imigração.

Palavras-chave do autor: século XIX, tolerância religiosa. 


\section{Introducción}

Consumada la Independencia varios aspectos fueron propuestos y discutidos para ser implementados en los nacientes países. Dos de ellos son de nuestro interés: la inmigración de extranjeros para, entre otras cosas, poblar el territorio y contribuir con el adelanto material y moral de las nacientes repúblicas, y la tolerancia religiosa como derecho y garantía individual.

El artículo muestra la relación que se propuso en México y la Nueva Granada, actual Colombia, entre la tolerancia religiosa y la inmigración a finales de la década de 1840 cuando en ambos países se plantearon proyectos para fomentar la inmigración y de paso la tolerancia religiosa. Esto es que la tolerancia religiosa resultaba ser un factor fundamental para promover la inmigración. Desde la Independencia se esbozó de manera clara esa relación. Sin embargo, es a raíz de la propuesta de esos proyectos de colonización, en Nueva Granada por medio de la Ley del 2 de junio de 1847 y en México con un proyecto promulgado en el segundo semestre de 1848, cuando la discusión sobre las bondades o perjuicios que traería tanto la tolerancia religiosa como la inmigración se vio con más fuerza. Es de anotar que los proyectos de colonización planteaban explícitamente la tolerancia religiosa cuando, constitucionalmente hablando, no estaba permitida. ${ }^{1}$

Antes de la década de 1840 ya se habían presentado debates por la tolerancia religiosa en México y la Nueva Granada, aunque no necesariamente se relacionaban con la inmigración. En la década de 1820 por la presencia en ambos países de colporters como Diego Thomson quien promovió la Sociedad Bíblica y el método lancasteriano; ${ }^{2}$ en Colombia por la presencia de la legión británica en la campaña independentista; o los tratados de comercio, amistad y circulación firmados por ambos países con potencias como Gran Bretaña; en México, en 1831, por la publicación del libro del guayaquileño Vicente Rocafuerte, Ensayo sobre tolerancia religiosa, lo que le valió

\footnotetext{
${ }^{1}$ En 1824 se aprobó la que fue la primera constitución de México, la cual fue remplazada en 1835 dando inicio al sistema centralista. Sin embargo, en 1846 la constitución de 1824 fue restablecida. En el artículo tercero de esta se indicaba que "La religión de la nación mexicana es y será perpetuamente la católica, apostólica romana. La nación la protege por leyes sabias y justas, y prohíbe el ejercicio de cualquier otra”, lo cual impuso la intolerancia religiosa. Véase: Las Constituciones de México, 1814-1989 (México: H. Congreso de la Unión, Comité de Asuntos Editoriales, 1989) 75. En la Constitución Política de la República de la Nueva Granada de 1843 dos artículos fueron dedicados al asunto de la religión. El número 15: "Es también un deber del Gobierno proteger a los granadinos en el ejercicio de la Religión Católica, Apostólica, Romana"; el número 16: "La Religión Católica, Apostólica, Romana es la única cuyo culto sostiene y mantiene la república". Constitución Politica de la República de la Nueva Granada (Bogotá: Imprenta del Gobierno, 1843) 334.

${ }^{2}$ Carlos Martínez Silva, James Thomson. Un escocés distribuidor de la Biblia en México, 1827-1830 (México: Maná, Museo de la Biblia, 2013); Pablo Moreno, "Presencia protestante en el nacimiento de la república colombiana: el caso de la Sociedad Bíblica Colombiana, 1825”, Ecos del Bicentenario. El protestantismo y las nuevas repúblicas latinoamericanas, ed. Carlos Mondragón (Buenos Aires: Ediciones Kairos, 2011), 115-141.
} 
a su autor ser enjuiciado, y a la postre ser declarado inocente. ${ }^{3}$ Desde el punto de vista historiográfico la lectura sobre la tolerancia religiosa en ambos países para los primeros años posteriores a la Independencia es desigual, siendo Colombia el de menor desarrollo. ${ }^{4}$

A finales de la década de 1840, y sobre la tolerancia religiosa, podemos ver por lo menos dos formas de afrontar el problema, las que debaten en lo que podría considerarse como un escenario temporal de transición. La intolerancia religiosa entendida como de origen divino, característica de la sociedad pactista del mundo colonial, y el iusnaturalismo, entendido como base de la defensa de los derechos y

\footnotetext{
${ }^{3}$ Vicente Rocafuerte, Ensayo sobre tolerancia religiosa (México: Imprenta de M. Rivera, 1831).

${ }^{4}$ Gustavo Santillán, "Discusiones sobre la tolerancia religiosa en México. 1821-1827” (Tesis, Licenciatura en Historia, UNAM, 1997); Gustavo Santillán, "La tolerancia religiosa en México, 1833-1849” (Tesis, maestría en Historia, UAM, 2000); Gustavo Santillán, "Tolerancia religiosa y moralidad pública, 18211831”, Signos históricos.7 México, (enero-junio, 2002): 87-104; Gustavo Santillán, "La secularización de las creencias: discusiones sobre la tolerancia religiosa en México", Estado, Iglesia y sociedad en México, siglo XIX, coords. Álvaro Matute y otros (México: Miguel Ángel Porrúa, UNAM, 1995); Emilio Martínez Albesa, "El primer debate sobre tolerancia religiosa en el México independiente, 1823-1824", Alpha Omega 9.3 (2006): 475-506; Enrique Krauze, "Debates históricos sobre la tolerancia", Letras Libres.142 (México, 2010): 18-21; Jean-Pierre Bastian, "Leyes de Reforma, ritmos de secularización y modernidad religiosa en México, siglo XIX", Las leyes de Reforma y el Estado laico. Importancia histórica y validez contemporánea, coord. Roberto Blancarte (México: El Colegio de México, 2013) 141164; Jean-Pierre Bastian, "Tolerancia religiosa y libertad de culto en México, una perspectiva histórica", Cuadernos del Instituto de Investigaciones Jurídicas. Derecho fundamental de libertad religiosa (México: UNAM, 1994) 17-36; Fernando Alanís Enciso, "Los extranjeros en México, la inmigración y el gobierno: ¿tolerancia o intolerancia religiosa?, 1821-1830”, Historia Mexicana 45.3 México (1996): 539-566; Dietir Berninger, "Immigration and religious toleration: a Mexican dilemma 1821-1860", The Americas 32.4 (abr., 1976): 549-565; Dietir Berninger, La inmigración en México (1821-1857) (México: Sep setentas, 1974); Abraham Téllez Aguilar, "Protestantismo y política en México en el siglo XIX", El protestantismo en México (1850-1940). La iglesia metodista episcopal, coords. Laura Espejel López y Rubén Ruiz Guerra (México: INAH, 1995); Abraham Téllez Aguilar, Proceso de introducción del protestantismo en México desde la Independencia hasta 1884 (Monografía de licenciatura, UNAM, 1989); Evelia Trejo, "La introducción del protestantismo en México: aspectos diplomáticos", Estudios de Historia Moderna y Contemporánea de México 9 (México, 1988); Brian Connaughton, "The Enemy Within: Catholics and Liberalism in Independent Mexico, 1821-1860", The Divine Charter. Constitutionalism and Liberalism in Nineteenth Century, ed. Jaime Rodríguez (Lanham: Rowman and Littlefield Publishers, 2006) 183-202. Para mencionar unos pocos.

Para el tema específico que tratamos en este artículo no existe bibliografía colombiana. Encontramos, eso sí, textos que muestran de manera general el problema de la tolerancia religiosa en el país. Aquí referenciamos los que aluden al problema para antes de 1853, año en el que se legisló la libertad religiosa. Carlos Arboleda Mora, Historia del pluralismo religioso en Colombia (Medellín: Universidad Pontificia Bolivariana, 2002) 23-35; Carlos Arboleda Mora, Pluralismo, tolerancia y religión en Colombia (Medellín: Universidad Pontificia Bolivariana, 2011) 65-93; Jose David Cortés Guerrero, "Argumentos por la tolerancia religiosa en Colombia, 1832-1853”, Historia y Sociedad 33 Medellín (julio-diciembre, 2017): 45-76; Andrey Coy Sierra, "Tolerancia religiosa en Bogotá entre 1849 y 1854", Historia Crítica 33 (Bogotá, 2007): 74-97; Andrey Coy Sierra, Tolerancia religiosa en Bogotá y la revolución liberal de medio siglo (1849-1854), (Monografía, pregrado en Historia, Universidad Nacional de Colombia, 2004); Pablo Moreno Palacios, Por momentos hacia atrás... por momentos hacia adelante. Una historia del protestantismo en Colombia, 1825-1945 (Cali: Universidad San Buenaventura, 2010) 35-55; Javier Rodríguez, "Primeros intentos de establecimiento del protestantismo en Colombia", Historia del cristianismo en Colombia, Dir. Ana María Bidegain (Bogotá: Taurus, 2004) 287-294; Fabio Hernán Carballo, La meretriz inmaculada. Discursos anticatólico y antiprotestante en la Colombia decimonónica (Bogotá: Editorial Universidad del Rosario, 2017) 1-38.
} 
garantías individuales, entre los que está la tolerancia religiosa. Es un escenario de transición porque aún pervive la visión de derecho divino, pero ya comienza a verse con más fuerza la defensa de derechos y garantías individuales que antes no aparecían. En México está un aditamento particular, la guerra con Estados Unidos entre 1846 y 1848 , país relacionado con el protestantismo, y la pérdida de la mitad del territorio en ese conflicto.

Como hipótesis planteamos que la propuesta de la tolerancia religiosa se revistió de sentido práctico pues fue enunciada como indispensable para la inmigración de extranjeros. Esto porque la elite política liberal de ambos países, aunque con matices los más radicales eran más propensos--, prefería que los inmigrantes vinieran de países protestantes influenciados por la Reforma ya que argumentaban que ella era una de las responsables del progreso y la civilización que se vivía en buena parte de Europa Occidental y Norteamérica. De esta forma se criticaba explícitamente tanto a España como a la herencia colonial que ella había dejado en América, a las que se ligaba no solo con la intolerancia religiosa sino también con el atraso material y moral con el que nacieron las nuevas repúblicas.

Siguiendo con lo anterior, el debate por la tolerancia religiosa vinculada con la inmigración está inmerso en la reconfiguración que significaron las nuevas realidades republicanas en donde los nacientes Estados en formación, con una institucionalidad débil, confrontaban a la Iglesia católica, institución que se mostraba fuerte y que provenía de la época colonial. Esa confrontación, que es muy compleja, se presenta en múltiples escenarios y tiene como fondo esencial imponer formas homogéneas de ver y vivir el mundo. Esas formas de ver el mundo están permeadas de política y de religión, y por ello no es extraño que al hablar de tolerancia religiosa como un derecho individual y de inmigración como un mecanismo de progreso material y moral, tanto política como religión salten a la arena de la discusión, no por ellas mismas, es obvio, sino como discursos de actores específicos, por ejemplo, la Iglesia católica como institución, políticos y publicistas, entre otros.

La selección de los casos mexicano y neogranadino para ser abordados comparativamente obedece a varias razones: primera, la coincidencia en la propuesta de leyes y proyectos de inmigración y de colonización, la forma como ellos fueron promovidos, generalmente, por el liberalismo y el rechazo generado tanto por la institución eclesiástica, así como por sectores conservadores. A esto se suma que en ambos países el papel que jugaría la Iglesia católica en la historia del siglo XIX sería fundamental.

Segunda, al hecho de que ambas propuestas de inmigración y colonización se promovieran unos años antes del grueso de las reformas de mitad de siglo, es decir, fueron, como algún autor ha dicho para México, una especie de reforma antes de las reformas. ${ }^{5}$ Tercera, y siguiendo con lo anterior, a la necesidad de continuar el

${ }^{5}$ David K. Burden, "Reform Before La Reforma: Liberals, Conservatives and the Debate over Immigration, 1846-1855", Mexican Studies/ Estudios Mexicanos 23.2 (Oakland, 2007): 284-300. 
estudio de las tensiones generadas por propuestas de corte liberal en ambos países a mediados del siglo XIX. ${ }^{6}$ Cuarta, a la también necesidad de plantear inquietudes investigativas en donde se muestre cómo las discusiones por la tolerancia religiosa, la libertad religiosa y la libertad de cultos traían consigo complejizar las sociedades mexicana y neogranadina al introducir tópicos vinculados con principios de laicidad y secularización como lo fueron la separación Estado-Iglesia, el registro civil, el matrimonio civil y la secularización de los cementerios, entre otros. Esto, como es de suponer, abre el panorama para hacer comparaciones con otros escenarios de América Latina, por ejemplo: el Cono Sur, en donde la gran inmigración parece que no generó reacciones tan fuertes por la eventual presencia de no católicos, y facilitó, de mejor manera, la discusión e implementación de medidas conducentes a la laicidad y la secularización. ${ }^{7}$ De igual manera nos permite ubicar el problema específico, tolerancia religiosa e inmigración en México y Nueva Granada, en medio de la crisis que vivía Occidente en ese momento, caracterizada, entre otros aspectos, por la carencia de alimento generada por la afectación de cosechas de la papa en Europa occidental, lo que estaba motivando el desplazamiento poblacional hacia otras regiones del mundo. Es decir, la coincidencia de propuestas de inmigración obedece a la lectura del escenario internacional.

El artículo está dividido en dos partes. En la primera mostramos la forma como se plantearon la inmigración y la tolerancia religiosa, destacando las bondades de ellas y la relación existente entre ambas. En la segunda exponemos las reacciones opuestas a la tolerancia religiosa vinculada con la inmigración de no católicos. Si bien parece que la presentación de los argumentos en favor y en contra es esquemática obedece a la manera como los actores protagonistas de las discusiones presentaban esos argumentos, como si de opuestos se tratara. Sin embargo, entre esos opuestos podían surgir matices que si bien no cedían del todo con el oponente podían llegar a generar espacios de flexibilidad. Un ejemplo es que quienes se oponían a la inmigración podían estar de acuerdo si ella provenía de la Europa católica.

Debemos anotar que la inmigración a gran escala fracasó en ambos países, aunque para el caso colombiano es necesario profundizar con más detalles en el estudio de los discursos, los imaginarios y las representaciones que se construyeron sobre la

\footnotetext{
${ }^{6}$ Pueden verse varios trabajos míos en esa dirección, entre ellos: José David Cortés Guerrero, ““Viva la religión y mueran sus enemigos": oposición a la tolerancia religiosa en México a mediados del siglo XIX”, Anuario Colombiano de Historia Social y de la Cultura.33 Bogotá (2006): 209-246; José David Cortés Guerrero, "La Escuela Nacional Preparatoria de México y la Universidad Nacional de los Estados Unidos de Colombia: Lectura comparada de dos proyectos educativos modernizadores; 1867-1878", Anuario Colombiano de Historia Social y de la Cultura.34 Bogotá (2007) 323-383; José David Cortés Guerrero, "Lectura comparada de una época de reformas liberales. México y Colombia a mediados del siglo XIX", Las Leyes de Reforma y el Estado laico: importancia histórica y validez contemporánea, coord. Roberto Blancarte (México: UNAM, El Colegio de México, 2013); José David Cortés Guerrero, "Las costumbres y los tipos como interpretaciones de la historia: Los mexicanos pintados por símismos y el Museo de cuadros de costumbres", Estudios de Literatura Colombiana.33 Medellín (julio-diciembre, 2013): 13-36.

${ }^{7}$ Como ejemplo puede verse el caso uruguayo: Gerardo Caetano, La secularización uruguaya, 1859-1919 (Montevideo: Taurus, 1997).
} 
inmigración. ${ }^{8}$ El fracaso de la inmigración no debe importarnos pues lo que queremos resaltar, y en eso coincidimos con Erika Pani, es que las discusiones por un tópico como la inmigración, y en nuestro caso puntual su relación con la tolerancia religiosa, nos permite detallar diversas formas de ver el mundo, así como proyectos de cómo deberían ser el Estado y la sociedad. ${ }^{9}$

Sobre el tópico que presentamos en este artículo algunos historiadores mexicanos han discurrido con variedad de argumentos. En algunos casos se presenta el problema de manera general sin enfatizar en la relación clara entre tolerancia religiosa e inmigración, quedándose en las interpretaciones y visiones sobre los que potencialmente serían los inmigrantes, es decir los protestantes. ${ }^{10}$ En otros casos la discusión por la tolerancia religiosa finalizando la década de 1840 se presenta en un panorama más amplio indicando que hace parte de un preludio a lo que serán las reformas liberales en la segunda mitad de la década de $1850 .{ }^{11}$

En cuanto al contexto histórico ambos países se están formando después de la Independencia, sin embargo, a pesar de la debilidad institucional que esa formación suponía encontramos diferencias importantes. México comienza la década de 1840 saliendo de una intervención extranjera, la francesa, en la Guerra de los pasteles. Igualmente había asumido en 1835 el sistema centralista. De igual manera, con las Bases de Tacubaya de 1841, se instauró una dictadura provisional (1841-1843) y se redactó en 1842 una nueva constitución que no entró en vigor. En 1843 se redactaron las Bases Orgánicas, las que estuvieron vigentes hasta 1846. En ellas se reforzó el poder ejecutivo y la intolerancia religiosa. Para 1846 la crisis política era generalizada. Antonio López de Santa Anna, el hombre fuerte del país salió exiliado a Cuba pero sus aliados conspiraron a favor de él con lemas como "Santa Anna y federación". Texas, que se había separado una década antes, se anexó a Estados Unidos. Y en ese punto es que la naciente potencia del norte amenazó a México comenzando una guerra que resultaría en la pérdida de más de la mitad del territorio. ${ }^{12}$

La Nueva Granada inició la década de 1840 en medio de la primera guerra civil del país, la de los Supremos, la cual finalizó en 1841 con el triunfo de las fuerzas

\footnotetext{
${ }^{8}$ Frédérick Martínez, "Apogeo y decadencia del ideal de la inmigración europea en Colombia, siglo XIX”, Boletín Cultural y Bibliográfico 34.44 Bogotá (1997): 3-45.

${ }^{9}$ Érika Pani, Para pertenecer a la gran familia mexicana: procesos de naturalización en el siglo XIX (México: El Colegio de México, 2015) 13-19.

${ }^{10}$ Estela Roselló Soberón, “Catolicismo versus protestantismo en los intentos de 'reencantar' el mundo: la patria católica frente a la amenaza de la tolerancia religiosa. México, 1848", Itinerarios e intercambios en la historia intelectual de México, coomps. Miruna Achim y Aimer Granados (México: CONACULTA, UAM-C, 2011) 98-100; Alberto del Castillo Troncoso, "El debate en torno a la tolerancia de cultos en México durante la coyuntura de la posguerra (1848-1849)", Historia y Grafía.14 México (2000) 17-34.

${ }^{11}$ Burden, "Reform Before La Reforma" 284-300.

${ }^{12}$ Pueden verse: José Antonio Serrano Ortega y Josefina Zoraida Vázquez, "El nuevo orden, 1821-1848”, Nueva Historia General de México (México: El Colegio de México, 2010) 397-442; Andrés Lira y Anne Staples. "Del desastre a la reconstrucción republicana, 1848-1876", Nueva Historia General de México (México: El Colegio de México, 2010) 443-486; y, coord. María Luna Argudín, México. La construcción nacional (1830-1880) (México: Taurus, Fundación MAPFRE, 2012).
} 
gubernamentales comandadas por Pedro Alcántara Herrán quien ese mismo año fue elegido presidente. Herrán continuó con el civilismo implementado la década anterior por Francisco de Paula Santander, consistente en el respeto, por lo menos formal, de las instituciones y de los mandatos presidenciales. Esta constituye una diferencia fundamental con respecto a México, pues en Colombia se evitó que los gobernantes intentaran perpetuarse en el poder como sí pasó con Antonio López de Santa Anna, y desde 1877 con Porfirio Díaz. Incluso el experimento federalista ejemplificado en la Constitución Política de 1863 (1863-1886) redujo el poder del presidente considerablemente.

En 1845, Herrán entregó la presidencia a Tomás Cipriano de Mosquera quien gobernó sus respectivos cuatro años hasta 1849, año en que entregó la jefatura del Estado a José Hilario López, candidato del recientemente creado Partido Liberal. Es una década de relativa estabilidad, mucho mayor si la comparamos con México, aunque aún sigue siendo válida la reflexión, con algunos matices, que hace tres décadas hicieron los historiadores Uribe y Álvarez al indicar que los primeros años republicanos, hasta las reformas de mitad de siglo, están por investigarse a profundidad. ${ }^{13}$ También el país comenzó a insertarse a la economía mundial por medio de la agroexportación y en materia política surgieron los dos partidos tradicionales, Liberal (1848) y Conservador (1849), que gobernaron alternadamente hasta finales del siglo XX. Es, igualmente, la década de gestación de las reformas liberales de medio siglo, las cuales comenzaron a concretarse hacia 1850, y las que, como hemos mencionado en otra parte, merecen revisiones profundas pues han sido sobrevaloradas por la historiografía colombiana. ${ }^{14}$

Los proyectos de inmigración que contenían explícitamente la tolerancia religiosa a finales de la década de 1840, en México y Nueva Granada, nos muestran aspectos que fueron característicos en esa época de reformismo liberal. El primero es el afán de las elites, sobre todo las reformistas liberales, de destruir la herencia colonial que ellas consideraban, desde su perspectiva, como la que impedía el progreso y la civilización. De esta forma, intelectuales liberales decimonónicos crearon la imagen de la Colonia como un escenario en donde la Corona española, por medio de sus representantes, y la Iglesia católica como institución, construyeron mecanismos que impidieron avances técnicos, científicos y económicos, así como la intolerancia religiosa, a la que consideraban como persecutora. Esto configuró la llamada leyenda negra sobre España, consistente en responsabilizar a los tres siglos de dominación colonial del atraso, las trabas y las taras con las que nacieron las nuevas repúblicas independientes. ${ }^{15}$ En ese sentido, puede entenderse el discurso culturalista en el que se veía al mundo anglosajón como el que debería imitarse al considerarlo vanguardia

\footnotetext{
${ }^{13}$ María Teresa Uribe de Hincapié y Jesús María Álvarez, Poderes y regiones: problemas en la constitución de la nación colombiana. 1810-1850 (Medellín: Universidad de Antioquia, 1987) 11-12.

${ }^{14}$ José David Cortés Guerrero, La Batalla de los siglos. Estado, Iglesia y religión en Colombia en el siglo XIX. De la Independencia a la Regeneración (Bogotá: Universidad Nacional de Colombia, 2016) 14 y 115-224.

${ }^{15}$ Esto tiene un impacto historiográfico pues buena parte de las interpretaciones que se elaboraron sobre la Colonia en el siglo XIX estuvieron marcadas tanto por esa leyenda negra como por su antagonista, la leyenda rosa. Esas interpretaciones han sido mecánicamente reproducidas hasta la actualidad.
} 
en cuanto a modernización y modernidad. De allí que los proyectos inmigratorios prefirieran que los migrantes procedieran de esa parte del mundo. El segundo es que esos proyectos pueden ser entendidos como un componente primigenio del reformismo liberal que caracterizó a ambos países en la década de $1850 .{ }^{16}$ En ese sentido, como ya ha sido planteado para el caso colombiano, reiteramos que se hace necesario desmitificar el peso de esas reformas de mitad de siglo y ver cómo antes de ellas las dinámicas transformadoras estaban presentes o por lo menos en gestación.

En la elaboración del artículo privilegiamos, como fuente, la impresa. Ella, por simple obviedad, circulaba con mayor facilidad, y a pesar del analfabetismo imperante en ambos países, se partía del principio que su contenido podía ser conocido por toda la gente debido a diferentes formas de lectura y transmisión del mismo. Esa fuente nos permite ver con claridad los ideales, las propuestas, los proyectos, las formas de ver e interpretar el mundo; así como los temores, miedos y angustias, inventados, sufridos y vividos, que tenían los distintos actores sociales que participaron en las discusiones sobre la tolerancia religiosa y la inmigración.

De las fuentes impresas vale la pena resaltar las representaciones, documentos consistentes en exponer ante autoridades u órganos de representación como el Congreso, las inquietudes de una, varias o un grupo considerable de personas. Generalmente las inquietudes expuestas discurrían sobre un punto esencial. Como veremos en el artículo, en México y en menor medida en la Nueva Granada, las representaciones exponían ante el ejecutivo y/o el legislativo las inquietudes, pero sobre todo mayoritariamente el rechazo, por la eventual presencia de no católicos en ambos países. Este tipo de fuente es valioso porque deja ver las formas como sectores diversos de la sociedad estaban imaginando y representando su existencia, es decir, cuáles eran sus formas de ver el mundo.

\section{Tolerancia religiosa e inmigración en los proyectos de colonización: Nueva Granada (1847) y México (1848)}

En 1846 se creó en México la Dirección de Colonización para promover la inmigración de extranjeros lo que significaría fomentar la ocupación de tierras baldías, aumentar

\footnotetext{
${ }^{16}$ La década de 1850 en México fue muy activa: la dictadura de Santa Anna, el Plan de Ayutla, la administración de Comonfort, la guerra de Reforma, las reformas impulsadas por Benito Juárez. Sobre el reformismo de mediados del siglo XIX en México, sobre todo en lo tocante a política y religión, pueden verse, entre otros, los siguientes textos: Jacqueline Covo, Las ideas de la reforma en México 1855-1861 (México: Universidad Nacional Autónoma de México, 1983); Silvestre Villegas Revueltas, El liberalismo moderado en México, 1852-1864 (México: UNAM, 1997); Brian Connaughton, “1856-1857: conciencia religiosa y controversia ciudadana. La conciencia como poder político en un "pueblo eminentemente católico"”, Prácticas populares, cultura política y poder en México, Siglo XIX, coord. Brian Connaughton, Brian (México: UAM-I/Juan Pablos, 2008) 395-464; Brian Connaughton, Entre la voz de Dios y el llamado de la patria. Religión, identidad y ciudadanía en México, siglo XIX (México: FCE, UAM-I, 2010); Gabriela Díaz Patiño, Católicos, liberales y protestantes. El debate por las imágenes religiosas en la formación de una cultura nacional (1848-1908) (México: El Colegio de México, 2016).

Para el caso colombiano pueden verse: Cortés Guerrero, La Batalla de los siglos 143-315; Fernán González, Poderes enfrentados. Iglesia y Estado en Colombia (Bogotá: Cinep, 1997).
} 
la población, y generar dinámicas de industrialización y agricultura a gran escala. ${ }^{17}$ Es de anotar que desde la Independencia en México se propuso la colonización por lo que el proyecto de 1848 no fue el primero. El 4 de enero de 1823 Agustín de Iturbide firmó la Ley General de Colonización. El 13 de febrero de ese año se reglamentó el ingreso de extranjeros a México estipulando que debían ser católicos. El 18 de agosto de 1824, después de proclamada la constitución política, se promulgó una nueva Ley General de Colonización, en la cual también se daba la posibilidad de que los colonos fueran inmigrantes, pero bajo la intolerancia religiosa la cual ya había sido estipulada en la constitución de ese año. También en 1824 el Gobierno comisionó a Vicente Rocafuerte y a Mariano Michelena para que negociaran en Inglaterra un tratado de comercio que permitiera la inmigración de artesanos cualificados. Para esa misma época se estaban brindando facilidades para que colonos estadounidenses se asentaran en el norte de México, lo que derivaría en los sucesos conocidos en relación con Texas y la pérdida del norte del país en la guerra con Estados Unidos entre 1846 y $1848 .{ }^{18}$ Este recuento rápido lo único que pretende es mostrar que desde el comienzo de su vida como país independiente en México se buscó el arribo de extranjeros.

Por su parte, desde 1832, cuando se creó la Nueva Granada después de la disolución de la Gran Colombia, varios proyectos de colonización fueron promovidos con el objeto de facilitar el arribo de extranjeros al país. De igual forma se organizaron compañías que deberían brindar condiciones mínimas a los inmigrantes. ${ }^{19}$ En la Nueva Granada se expidió el 2 de junio de 1847 una ley para favorecer la inmigración en cuyo articulado se estipulaba la tolerancia religiosa. ${ }^{20}$

En México, en 1848, una vez finalizada la guerra con Estados Unidos, y en la tónica de promover la colonización, Mariano Otero, ministro de relaciones interiores y exteriores, solicitó nuevos proyectos de colonización para lo cual era necesario legislar sobre tolerancia religiosa. La junta encargada del ramo planteó los proyectos de colonización el 5 de julio de ese año. Varios meses después, el 7 de octubre, una comisión de la Cámara de Diputados avaló los proyectos incluyendo lo referente a la tolerancia religiosa. Como era de esperarse, esta propuesta generó varios puntos de vista, debates, discusiones y confrontaciones entre quienes la apoyaron y los que la criticaron.

Un año antes, en la Nueva Granada, el primer gobierno de Tomás Cipriano de Mosquera (1845-1849) promovió un proyecto de colonización cuyo objetivo era atraer al país migrantes provenientes esencialmente de Europa y Estados Unidos, para

\footnotetext{
${ }^{17}$ Roselló Soberón, “Catolicismo” 98.

${ }^{18}$ Alanís, "Los extranjeros" 542-547; Moisés González Navarro, Los extranjeros en México y los mexicanos en el extranjero, 1821-1970, Tomo I (México: El Colegio de México, 1993) 45; Josefina Zoraida Vázquez, “Colonización y pérdida de territorio, 1819, 1857”, El poblamiento de México, Tomo 3, México en el siglo XIX (México: Secretaría de Gobernación, 1993) 114-133.

${ }^{19}$ Cortés Guerrero, “Argumentos” 53-56; Uribe y Álvarez, Poderes y regiones 187-203.

20 "Ley de 2 de junio de 1847, sobre inmigración de extranjeros", Colección de documentos sobre inmigración de extranjeros, reimpresos de la Gaceta de la Nueva Granada, número 611, del 13 de setiembre de 1847 (Bogotá: Imprenta de J. A. Cualla, 1847).
} 
encargarse de actividades agrícolas y artesanales. Para ello se daría libertad a agentes consulares y empresas para fomentar esa inmigración. ${ }^{21}$

La discusión por la tolerancia religiosa vinculada con los proyectos de colonización podría ser calificada hoy como "mediática" pues vinculó a diversos sectores de la población, no solo las élites políticas y económicas, a la jerarquía eclesiástica, sino también, sobre el papel, a ciudadanos comunes y corrientes que hicieron sentir sus opiniones por medio de representaciones que eran enviadas a los poderes ejecutivo y legislativo. También fue importante el empleo de los periódicos para tal fin. De allí lo mediático, pues se emplearon los impresos para ventilar las discusiones. Aquí es necesario hacer una aclaración pues la propuesta de colonización mexicana de 1848 movió mucha más opinión pública que la acaecida un año antes en la Nueva Granada, lo cual se refleja en el desequilibrio en cuanto al volumen de las fuentes existentes para ambos casos. Una posible explicación tiene que ver con la reciente guerra contra Estados Unidos lo que generó un temor basado en hechos reales, mientras que el caso colombiano refería más a un peligro latente pero no concreto.

A continuación, sintetizaremos los diversos argumentos que se esgrimieron en las discusiones por la tolerancia religiosa y la inmigración, motivadas por los proyectos de colonización. Estos argumentos no son excluyentes entre sí.

\section{La defensa de la colonización y la inmigración de extranjeros}

La colonización fue defendida, inicialmente, por quienes propusieron los proyectos de colonización. En México la junta formada para proponerlos se dio a esa tarea desde que Ciudad de México fue abandonada, después de la guerra, por los estadounidenses invasores. Es de anotar que el gobierno mexicano se dio cuenta de que era muy importante el aumento de la población por lo que creó la junta en noviembre de 1846. La junta se encargaría de elaborar los proyectos de colonización y el reglamento para esa actividad, siendo puntos neurálgicos en esos documentos la condición de los extranjeros y lo relativo a la religión, tanto así que el Gobierno mantuvo la idea de que esos temas deberían ser tratados también por el legislativo. ${ }^{22}$ Como también mencionamos atrás, una comisión de la Cámara avaló los proyectos incluyendo lo relativo a la tolerancia religiosa.

Quienes proponían la colonización la veían como la "idea salvadora", sobre todo por los momentos difíciles que continuamente vivía el país: para ese momento la reciente guerra con Estados Unidos y el conflicto de castas en Yucatán. Se pretendía con ella el aumento de la población, siendo vista como la "única esperanza" para mantener la unidad del territorio y para "alcanzar el resultado de su prosperidad y

\footnotetext{
21 "Ley de 2 de junio de 1847, sobre inmigración de extranjeros" 1-2.

${ }^{22}$ Proyectos de colonización, presentados por la junta directiva del ramo, al ministerio de relaciones de la República Mexicana en 5 de julio de 1848 (México: Imprenta de Vicente García Torres, 1848) 4-5.
} 
engrandecimiento". ${ }^{23}$ En ese sentido, la colonización no solo era la panacea, sino que también se mostraba como el pretexto perfecto para la introducción de población que ayudara a México a salir del atraso, no solo material y económico en el que se encontraba, sino también de tipo moral. Incluso puede pensarse que, al hacer alusión a la que es conocida como guerra de castas, se estuviese proponiendo, aunque no de manera abierta, el mejoramiento de la raza, responsabilizando a indígenas, y en general a los que no eran considerados blancos, de los problemas que vivía México.

En la Nueva Granada, a la par del argumento de ver la inmigración como idea salvadora, en donde con el arribo de hombres que serían capaces de introducir en el país tanto capitales como "industria, capacidad, ingenio, espíritu de empresa", se aludió a que ella destruiría el legado español, que había heredado en los habitantes neogranadinos "los perniciosos hábitos de pereza, rutina y holgazanería". Estos malos hábitos, insistimos, eran vistos por buena parte de los liberales como componente del "funesto legado del sistema colonial", que había dominado a la Nueva Granada hasta su Independencia. ${ }^{24}$ En ese sentido, patrocinar la inmigración extranjera era parte de la "leyenda negra" contra España que la historiografía decimonónica liberal promovió. ${ }^{25}$

En México, para que la colonización se pudiera efectuar era indispensable que los gobiernos suministrasen tanto las condiciones como los recursos necesarios, por lo que era importante que los extranjeros encontrasen "leyes hospitalarias", además de "libertad, seguridad y franquicias, que [concurriesen] a hacer para ellos atractiva esta tierra". Al compararse con Estados Unidos y la manera como fluían muchos europeos a ese país mientras que casi ninguno a México se afirmaba que éste estaba desacreditado en el extranjero por la continua zozobra en la que se vivía, ${ }^{26}$ aludiendo a las guerras civiles e internacionales que padecía el país desde la Independencia. El llamado que se hacía a la redacción de leyes que facilitaran la inmigración no debe extrañarnos. Finalizada la guerra con Estados Unidos uno de los puntos que debatían con ahínco las élites políticas era la necesidad de dotar a México de un cuerpo de instituciones y legal capaz de afrontar las nuevas realidades que vivía el país. Incluso, si fuese necesario, el cambio de la constitución. ${ }^{27}$

Una de las garantías que debería dársele a los colonos era la del respeto a la religión de cada uno de ellos. Así, en México, en la presentación de los proyectos de colonización la junta advertía que la religión de las colonias debía ser la de los colonos, pues

\footnotetext{
${ }^{23}$ Proyectos de colonización 3.

24 "Inmigración", La Época, (Bogotá) 14 de mayo de 1848: II.

${ }^{25}$ En esta línea resalta, entre otros, José María Samper, Apuntamientos para la historia política i social de la Nueva Granada desde 1810, i especialmente de la administración del 7 de marzo (Bogotá: Imprenta del Neo-Granadino,1853).

En contravía, también hubo una visión defensora del legado español y que se consolidó en el llamado hispanismo. Dos ejemplos son notorios: Sergio Arboleda, La república en la América española (Bogotá: Banco Popular, 1974 (1869)), y José Manuel Vergara y Vergara, Cuestión española. Cartas dirigidas al doctor M. Murillo (Bogotá: Imprenta de la Nación, 1859).

${ }^{26}$ Proyectos de colonización 6.

${ }^{27}$ Connaughton, Entre la voz de Dios 124-127.
} 
“[...] los que habrán de venir en más número no serán católicos, supuesto que la emigración se verifica principalmente de países protestantes", por lo que debería garantizarse la tolerancia religiosa la cual era calificada como "dogma práctico del mundo civilizado". ${ }^{28}$

Siguiendo con el caso mexicano, el punto más importante y en el que debemos hacer énfasis es que el proyecto de colonización proponía explícitamente la tolerancia religiosa y para promover la inmigración de quienes colonizarían las tierras brindadas para ello, era necesaria esa tolerancia. En este sentido, la tolerancia religiosa no se reducía al campo de las discusiones teóricas, filosóficas, e incluso históricas, sino que respaldadas en estas adquiría un sentido práctico. En esencia, la tolerancia religiosa se convertía en un instrumento útil y práctico que permitiría la posible ejecución de otros instrumentos también útiles y prácticos, la inmigración y la subsecuente colonización.

Por su parte, en la Nueva Granada, en el artículo sexto de la ley del 2 de junio de 1847 se indicaba que "[...] los inmigrados podrán ejercer el culto religioso que profesen, pública o privadamente, como les parezca más conveniente". ${ }^{29}$ En ese sentido, la tolerancia religiosa se mostraba como una virtud de las "sociedades democráticas, en lo que se colegía que era una cualidad de la civilización. ${ }^{30}$ Un año después de la ley, el entusiasmo por quienes defendían el proyecto fue tal que se llegó a proponer, en el capítulo de los derechos individuales de los granadinos, en un proyecto de constitución política para la Nueva Granada, que la nación le garantizaba a todo granadino "el derecho de profesar pública o privadamente su religión, y de ejercer su culto en sus respectivos templos". ${ }^{31}$ Debe resaltarse que el primer ítem de esos derechos individuales era este y que la libertad religiosa solo se legisló hasta la constitución política de 1853 .

Siguiendo con el caso neogranadino, en el decreto del 10 de septiembre de 1847, y que reglamentaba la citada ley del 2 de junio, se indicaba que los inmigrantes podrían disfrutar desde su llegada al país de libertad de conciencia y del ejercicio libre de sus creencias religiosas, pública o privadamente, sin que por ello fuesen molestados. Estaban eximidos del pago de contribuciones eclesiásticas, exceptuando las necesarias para mantener a sus propios pastores. ${ }^{32}$

La propuesta, en ambos países, de que los colonos manifestaran públicamente sus creencias religiosas tiene varias aristas para ver. La primera es que abiertamente contradecía la intolerancia religiosa legislada desde 1824 en México, y la vigente

\footnotetext{
${ }^{28}$ Proyectos de colonización 10. (Cursivas mías).

${ }^{29}$ Véase "Ley de 2 de junio" 2.

30 "Tolerancia", El Siglo, (Bogotá) 20 de julio de 1848: 2.

31 "Proyecto de constitución política para la Nueva Granada por F. G.”, El Siglo, (Bogotá) 3 de agosto de 1848: 2 .

32 "Decreto de ejecución de la lei sobre inmigración de extranjeros. Rufino Cuervo vicepresidente de la Nueva Granada, encargado del poder ejecutivo. En ejecución de la lei de 2 de junio de 1847, sobre inmigración de extranjeros", Colección de documentos 4-6.
} 
desde 1843 en Nueva Granada; la segunda es que iba más allá de lo que para ese momento se entendía mayoritariamente como tolerancia religiosa, es decir, permitir la práctica privada de cultos religiosos diferentes de la religión de carácter nacional.

También aparece como argumento para defender la tolerancia religiosa el que ella era fruto de su tiempo, es decir de la ilustración y del liberalismo, en donde hombres con diferentes creencias podían convivir respetando las de los demás. Así, se asemejaba la intolerancia a tiempos pasados, los cuales se relacionaban con la dominación colonial española. En este sentido el argumento reforzaba la confrontación entre lo moderno y lo viejo, entre el progreso y el atraso, entre la civilización y la barbarie, entre un mundo amplio en posibilidades versus la herencia española que el ideario liberal deseaba derribar. ${ }^{33}$ De aquí se puede colegir que quienes proponían la tolerancia religiosa y la inmigración de no católicos tenían la idea de que el mundo moderno, al que relacionaban con las revoluciones políticas, económicas y sociales, se había formado gracias a la Reforma protestante.

Otro aspecto práctico que podía traer, en materia religiosa, la colonización, era el de los matrimonios. Se advertía que con la tolerancia religiosa debería garantizarse la legalidad de los matrimonios contraídos, presentándose el escollo de que en esa materia se aplicaba lo establecido por la Iglesia católica, pero esto no podía aplicarse a quienes no eran católicos. ${ }^{34}$

Pasando directamente al proyecto mexicano puede verse en él el artículo 15, en el capítulo tercero, "del gobierno y administración de justicia de las colonias. De la religión, y de los matrimonios en las mismas colonias", el cual rezaba así: “[...] ningún culto es prohibido en las colonias de extranjeros, mas no se levantarán a expensas del gobierno nacional otros templos que los católicos. Los ministros de este serán además dotados de los fondos de colonización, durante los primeros diez años, y mediante esta dotación no podrán cobrar ningún género de derechos". ${ }^{35}$ Es decir, se permitiría la tolerancia religiosa pero no a costas del erario, salvo el sostenimiento de los ministros por un período de tiempo limitado. Así, parecía querer salvarse el obstáculo religioso para la inmigración y posterior colonización.

En el artículo siguiente, y haciendo alusión al tema del matrimonio, se indicaba que en las colonias de extranjeros bastaba el matrimonio civil para los efectos civiles, siendo "perpetuo e indisoluble en cuanto al vínculo", salvo por causas de adulterio juzgadas por los jueces y tribunales civiles. Tampoco podía contraerse matrimonio entre familiares ascendentes, descendientes, hermanos, con menores de edad, ni entre viudos si uno de ellos era el responsable de la muerte de su cónyuge. ${ }^{36}$ De esta forma también pretendía solventarse el tema de la familia como elemento fundamental de la sociedad.

\footnotetext{
33 “Inmigración", La Época, (Bogotá) 14 de mayo de 1848: II-III.

${ }^{34}$ Proyectos de colonización 11.

${ }^{35}$ Proyectos de colonización 30-31.

${ }^{36}$ Proyectos de colonización 31.
} 
Siguiendo con lo anterior observamos que un aspecto importante de la propuesta de tolerancia religiosa era que tocaba otros tópicos. Uno de ellos el del registro civil. Como con la tolerancia religiosa la población dejaría de ser exclusivamente católica surgían preguntas sobre cómo registrar y avalar aspectos de la vida de la persona como nacimiento, matrimonio y muerte. Allí el Estado debería asumir la responsabilidad del registro de esas circunstancias de la vida, pues se partía del principio que el matrimonio sacramental católico no serviría a las personas no católicas por lo que era necesario implementar el matrimonio civil. Igual sucedía con el bautismo y la sepultura de los muertos. Los hijos de los matrimonios no católicos deberían ser registrados ante el Estado. También rondaría la idea de la secularización de los cementerios.

A diferencia de México, en la ley de 1847 en la Nueva Granada no se contemplaba el matrimonio de personas no católicas. Sin embargo. en 1848 se discutió esa posibilidad cuando se presentó en el Congreso del país un proyecto de ley en esa dirección, en cuyo artículo primero se indicaba que se reconocían los "efectos civiles del contrato de matrimonio entre naturales y extranjeros no católicos" tras el cumplimiento de varios requisitos como la presentación de la solicitud ante la autoridad local pertinente, y la información previa del matrimonio para evitar obstáculo legal alguno. ${ }^{37}$ Fue necesario esperar hasta 1853 para la aprobación del matrimonio civil.

Es importante indicar que en el ideal inmigratorio relacionado con la tolerancia religiosa no cabía la posibilidad de promover la inmigración de regiones asiáticas. Se advertía que no debería patrocinarse la inmigración de indios o chinos coolies porque la idea era fomentar la industria por medio de los conocimientos de los inmigrantes, por su ejemplo de laboriosidad y sus buenas costumbres. Es decir, esa inmigración debía impulsar la civilización, aspecto que los coolíes no podrían cumplir porque eran “apáticos", poco comunicativos y su trabajo era como el de los esclavos. En el caso concreto, Nueva Granada perdería mucho con esta inmigración, pues se aceptaría una nueva especie de esclavitud o de mendicidad ya que con ellos no había punto medio ${ }^{38}$. Esto refuerza la premisa de que la inmigración proveniente de regiones protestantes estaba directamente relacionada con el mundo moderno y las transformaciones que en él se estaban presentando, las cuales podían imitarse gracias a la inmigración de personas provenientes de esas regiones.

Ahora bien, las condiciones parecían idóneas, además de ideales, para la inmigración y la subsecuente colonización. Sin embargo, fueron múltiples las voces que se levantaron contra esta iniciativa no por el hecho del poblamiento sino por aquellos a quienes estaban, en su mayoría, dirigidos los proyectos de colonización e inmigración, los protestantes.

\footnotetext{
${ }^{37}$ Proyecto de ley sobre matrimonio entre individuos no católicos (Bogotá: Imprenta de José A. Cualla, 1848) $1-2$

38 “Inmigración”, La Época, (Bogotá) 6 de agosto de 1848, III. La inmigración de protestantes europeos se prefería sobre la de otros no cristianos provenientes de Asia, a quienes se les consideraba inferiores en todo sentido, como lo muestra para Perú Pilar García Jordán. Allí se cuestionó el arribo de chinos coolíes, calificados de "raza degenerada". Pilar García Jordán, "Reflexiones sobre el darwinismo social. Inmigración y colonización, mitos de los grupos modernizadores peruanos (1821-1919)", Bulletin Institut Francaise d'études andines 21.2 París (1992): 965.
} 


\section{Oposición a la tolerancia religiosa vinculada con la inmigración}

A continuación, veremos los argumentos esgrimidos por quienes se opusieron a la tolerancia religiosa que conllevaba los proyectos de colonización que serían implementados por una previa inmigración masiva de extranjeros. Es de anotar que esos argumentos se cimentaban en el principio del rechazo a la relación existente entre tolerancia religiosa e inmigración.

El primer argumento es que la intolerancia religiosa era de derecho y origen divinos y por lo tanto la tolerancia religiosa estaba fuera de todo orden sagrado. Es decir, Dios determinó que solo podía existir una religión, y de tal forma solo una Iglesia era la garante de la misma. En esta dirección la tolerancia religiosa estaba basada en la oposición al designio divino. En una representación dirigida al Gobierno del país por parte del vicario capitular y del Cabildo metropolitano de la Ciudad de México puede verse esta explicación. Para la jerarquía eclesiástica era inconcebible no solo que se pusiera al mismo nivel legal a la "Religión de Jesucristo" con las falsas religiones que "los enemigos de Dios [habían] inventado", sino que era Dios quien había "mandado" se le rindiesen los "cultos públicos y privados", sin "permitir otros". ${ }^{39}$ Es decir, la intolerancia religiosa era de mandato divino, constitutiva del derecho divino. Pero no solo los eclesiásticos manejaban este argumento. Los laicos también lo esgrimieron. Los vecinos de Villa Mascota, en Jalisco, indicaban que la religión católica "que por especial beneficio de la Providencia" profesaban, era la "única que [derivaba] del cielo los títulos de su existencia". ${ }^{40}$

La visión que tenían los intolerantes en materia religiosa sobre la tolerancia religiosa además de contravenir el derecho divino también se asemejaba a la voz común del diccionario de autoridades de 1739. Allí se definía la tolerancia como "sufrimiento, paciencia, aguante", vinculados con la "permisión, y disimulo de lo que no se debiera sufrir sin castigo del que lo ejecuta". ${ }^{41}$ Es decir, la tolerancia religiosa era un padecimiento que no tendría razón de ser, y menos si quienes lo producían no recibían sanción por ello.

El segundo argumento es globalizador y hace referencia a que la tolerancia religiosa formaba parte de una conspiración mayor contra la religión e iglesia católicas. En una pastoral de 1848, Diego Aranda, obispo de Guadalajara, indicaba que tenía conocimiento que desde hacía mucho tiempo existía en el país una secta de hombres sin religión,

\footnotetext{
${ }^{39}$ Representación que hace el Illmo. Sr. vicario capitular y el Cabildo metropolitano al Supremo Gobierno de la Nación contra el proyecto de tolerancia de cultos (México: Imprenta de la Voz de la Religión, 1849) 4.

${ }^{40}$ Representación del vecindario de la villa de Mascota, contra la tolerancia de cultos (Guadalajara: Imprenta de Rodríguez, 1848) 4.

41 “Tolerancia”, Diccionario de autoridades, Tomo VI, 1739, http://web.frl.es/DA.html. (26/04/2017).
} 
[...] quienes con el pretexto de civilización, progreso en nuestra industria y en las artes con el aumento de la población, nos quieren privar del bien más precioso que poseemos y de las más dulces y deliciosas esperanzas de nuestro corazón; de la santa religión católica apostólica romana, pretendiendo introducir las falsas religiones, y que se establezca la tolerancia de ellas. ${ }^{42}$

Esas falsas religiones eran defendidas por protectores "públicos y secretos del error y de las revoluciones". ${ }^{43}$ La revolución, como es obvio, significaba trastocar el mundo establecido por designio divino.

En el mismo sentido se manifestaron tanto el ayuntamiento como los vecinos de Teocuitatlán, Jalisco, quienes, dirigiéndose al presidente del país, demandaban justicia contra "cierta clase de perversos" que querían destruir a la nación mexicana. Esos perversos creían "estúpidos" a los mexicanos, "llamando indistintamente a los extranjeros a poblar nuestro territorio, y permitiéndoles el ejercicio público de sus falsas religiones". ${ }^{44}$ Según esta lógica, y como aparece en otra representación, México se mantenía católico a pesar del empeño que desde 1821 algunos habían tenido por descatolizarlo y hacerlo protestante, "deísta y aún ateo". ${ }^{45}$ En ese sentido, algunos habitantes de Puebla indicaban que la aprobación del "culto público de cualesquiera sectarios sería un ataque directo a la religión católica, apostólica, romana, única verdadera, fundada por el espíritu de nuestro divino Salvador" ${ }^{46}$

La idea de que la Iglesia y la religión católica estaban en constante peligro y en confrontación con sus enemigos formaba parte de la explicación sobre el complot contra ellas, y rondaba en ambos países. Esto es que desde el principio ambas tenían que enfrentarse a fuerzas que le eran opositoras. Así, en la Nueva Granada se explicaba que cuando la Iglesia y la sociedad eran atacadas por los que consideraba errores surgían instituciones religiosas para hacerles frente. Cuando los albigenses "sembraban en la sociedad elementos de destrucción", la Iglesia aprobó las órdenes de San Francisco y de Santo Domingo. Para afrontar los errores del siglo XVI se creó la congregación de San Maun entre los benedictinos. En 1521 se creó a los

\footnotetext{
${ }^{42}$ Diego Aranda, Pastoral del Illmo. Sr. Dr. D. Diego Aranda, dignísimo obispo de Guadalajara a sus diocesanos, contra la introducción de las falsas religiones en el país (Guadalajara: Imprenta de Rodríguez, 1848) $1-2$

${ }^{43}$ Aranda, Pastoral 2.

${ }^{44}$ Representación que el ayuntamiento y pueblo de Teocuitatlan hace al Excmo. Sr. Presidente de la República para que se oponga a la admisión de tolerancia de cultos (Guadalajara: Imprenta de Manuel Brambilla, 1849) 1.

${ }^{45}$ Representación que el ayuntamiento y vecindario del mineral de Guachinango hace al supremo gobierno de la unión contra la tolerancia de cultos (Guadalajara: imprenta de Rodríguez, 1849) 1. El número de representaciones en el Estado de Jalisco contra la tolerancia religiosa es alto porque en la Gaceta Oficial del Estado se publicó el dictamen a favor de esa tolerancia lo que forzó la aparición de numerosas voces en contra, las cuales se expresaban por medio de representaciones. Véase Alma Dorantes, Intolerancia religiosa en Jalisco (México: Instituto Nacional de Antropología e Historia, Dirección de Centros Regionales, Centro Regional de Occidente, 1976) 114.

${ }^{46}$ Representación que los habitantes de Puebla elevan al soberano Congreso de la Unión, contrariando los conatos que para establecer la tolerancia religiosa en nuestro pais, aparecen hoy desgraciadamente (Puebla: Imprenta de Juan Nepomuceno del Valle, 1848) 3.
} 
teatinos, en 1532 los bernavitas. También se creó una "congregación que eclipsó a todas las otras", la Compañía de Jesús. ${ }^{47}$ No era gratuito que en el presunto peligro que era la inmigración de no católicos al país se recurriera a esta referencia histórica para indicar que, independientemente del peligro que afrontaran, religión e Iglesia católicas estaban preparadas para la confrontación. A esto se sumaba, que se tenía la idea y el imaginario de que la confrontación con los enemigos de la Iglesia y de la religión era de carácter universal, esto es que los combates que se presentaban en México y la Nueva Granada formaban parte de un escenario mundial. De esta forma se puede entender el pontificado de Pío IX que, coincidencialmente, comenzaba en esta época, 1846.

El tercer argumento indica que, legalmente hablando, no podía aceptarse la tolerancia religiosa pues en ambos países solo era permitido el catolicismo romano. En México, más allá de hacer alusión a la historia legal del país o a la manera como esa prescripción aparecía tanto en la constitución de la federación como en las de los estados lo que también se quería era la promoción de sanciones para quienes infringieran la norma. Así, vemos cómo se pedía castigo severo a quien atentase contra la religión nacional, que estaban "obligados a guardar y venerar todos los que [quisieran] pertenecer a la gran familia". ${ }^{48}$ Pertenecer a "la gran familia mexicana"49 parecía ser una expresión recurrente en la época y daba a entender, para nuestro caso, que el lazo de unión de esa familia era la religión.

Por su parte, en la ciudad de Túquerres, al suroccidente de la Nueva Granada, quienes se oponían a la tolerancia religiosa relacionada con la ley de inmigración, elevaron una representación en donde también indicaban la necesidad de ver destruidas a las "sectas contrarias", en lugar de tolerarlas. Presumiblemente siguiendo a Santo Tomás de Aquino indicaban que los "herejes" no solo deberían por su pecado ser excluidos de la Iglesia sino también ser "arrojados del mundo". En ese sentido, debería castigarse a los "sacrílegos, a los blasfemos, a los impíos". 50

Volviendo al caso mexicano, además de los textos constitucionales también se esgrimió un discurso jurídico basado no solo en la filosofía del derecho sino también en la soberanía nacional. Así, se indicaba que la tolerancia religiosa no respetaba la "voluntad nacional" y que ninguno de los poderes, por ejemplo, el legislativo, tenía las facultades soberanas para introducir modificaciones en esa materia. ${ }^{51}$ Así las cosas, en varias representaciones se indicaba que el congreso mexicano, quien representaba a la nación, no había recibido dentro de sus facultades la de decretar la tolerancia de

\footnotetext{
47 "La libertad y Lutero. Artículo segundo", El Filotémico, (Bogotá) 1 de diciembre de 1850: 13.

${ }^{48}$ Representación que el ayuntamiento y pueblo de Teocuitatlan 7.

${ }^{49}$ Exposición del ilustre ayuntamiento y vecinos de Córdova, contra la tolerancia de cultos (Puebla: Imprenta de J. N. Valle, 1848) 1. Véase: Pani, Para pertenecer.

50 "Honorables representantes y senadores", El clamor de la verdad, (Bogotá) 16 de abril de 1848: 3-4.

${ }^{51}$ Representación del ayuntamiento y vecindario de la villa de Etzatlán a las augustas Cámaras, contra la tolerancia de cultos (Guadalajara: Imprenta de Rodríguez, 1848) 3.
} 
cultos, porque de ser así el pueblo y sus representantes deberían renunciar a su fe..$^{52}$ Esto debido a que la gran mayoría de los mexicanos, aunque se partía del principio que era la totalidad, eran católicos. Por ello mismo se exhortaba vehementemente a los legisladores a cumplir su deber como católicos: “¡Legisladores Mexicanos! ¡Legisladores católicos! Orillados estáis a la profundidad de un precipicio donde os despeñáis, sí faltos de previsión, o por importunar exigencias, decretáis la tolerancia religiosa en nuestra patria". Ahora bien, si la tolerancia religiosa era aprobada, México corría el peligro de convertirse en una "cloaca de abominación". ${ }^{53}$

Siguiendo con lo anterior, algunos creían que no era cierto que la legislación evitase el arribo de extranjeros. Se afirmaba que no se encontraría una sola población "en que no [existiesen] muchos alienígenas" a los cuales nunca se les preguntaba por la religión que profesaban. La responsabilidad de que no llegasen extranjeros a México era de la situación política, las "continuas revueltas" y a la amenaza contra la propiedad privada. $^{54}$

Esto hacía parte de una discusión que había sido propuesta por John Locke finalizando el siglo XVII, consistente en indicar si el legislador tenía o no derecho de legislar sobre la religión de los individuos, teniendo en cuenta que la relación entre cada cual y dios era esencialmente privada. Para Locke, el legislador no tenía derecho de hacerlo. ${ }^{55}$ Como vemos aquí, los defensores de la intolerancia religiosa en ambos países creían que los legisladores, al pertenecer a un país católico y representar a su población, sí deberían determinar que la única religión que debería profesarse era la católica romana.

El cuarto argumento indicaba que la inmigración, y por ende la tolerancia religiosa, vendían falsas esperanzas de riqueza, felicidad y prosperidad. En México, el obispo de Guadalajara, Diego Aranda, afirmaba que la novedad de la tolerancia religiosa era difundida con "ideas lisonjeras de felicidad, imaginarias de ilustración, y [...] con engañosas esperanzas de riqueza y de abundancia, con falsas teorías, con sublimes discursos". ${ }^{56}$ Desde la óptica del jerarca, esas falsas teorías y sublimes discursos estaban vinculados directamente a la introducción de cultos falsos y los proyectos que para ello había como, por ejemplo, los "de colonización, presentados por la junta directiva del ramo al ministerio de relaciones y publicados por la prensa". Tanto la tolerancia religiosa como la inmigración de no católicos, insistía el prelado, querían mostrarse como de una "necesidad imprescindible para el bien y prosperidad de la nación". ${ }^{57}$ En este sentido, lo que la inmigración y la tolerancia religiosa pretendían

\footnotetext{
${ }^{52}$ Representación del ayuntamiento y vecindario de la villa de Etzatlán 6.

${ }^{53}$ Representación que los vecinos de Autlan dirigen al supremo gobierno nacional contra la tolerancia de cultos en el pais (Guadalajara: Imprenta de Rodríguez, 1849) 4-5.

${ }^{54}$ Representación que han elevado a las augustas cámaras de la nación los vecinos de Orizava, contra el proyecto de introducir en la República la tolerancia de cultos (México: Tipografía de R. Rafael, 1849) 9.

${ }_{55}^{5}$ John Locke, Ensayo y carta sobre la tolerancia (Madrid: Alianza, 2011) 26-30.

${ }^{56}$ Aranda, Pastoral 2.

${ }^{57}$ Aranda, Pastoral 6.
} 
era subordinar la religión "al progreso material", como si este fuera lo más importante a lo que aspiraría el hombre en sociedad. ${ }^{58}$ Así, podía afirmarse, como se hizo en una representación, que los enemigos de la "quietud" mexicana, buscando ejecutar sus "extravagantes utopías", hacían promesas de "progreso, ventura y bienestar indefinibles", pero lo que traerían proyectos como los de colonización por extranjeros sería lo contrario: "semillero de discordias". ${ }^{59}$ Así, se confrontaba la dinámica que generaría la inmigración con industria, comercio activo, agricultura productiva, con la "quietud" mexicana, relacionada con pasividad, letargo, pero, sobre todo, una forma de vida tranquila y sosegada.

Siguiendo con la lógica del progreso material, y con el caso mexicano, en una representación se advertía que ella no produciría los resultados esperados. Incluso, en ese mismo documento se invitaba al lector a que hiciese el ejercicio de suponer que si se obtenía el progreso material, comercio, industria y artes, valdría la pena que aquél remplazara al progreso moral que provenía de la verdadera religión. De esta forma se afirmaba que "[...] el progreso moral [estaba] en razón inversa del progreso físico o material para la felicidad del género humano" ${ }^{60}$ Así, en el orden moral se indicaba, entre otras cosas, que "la poligamia podría establecerse siguiendo las opiniones de Melaneton, y demás fundadores de la reforma: la santidad del matrimonio desaparecería". De igual forma los "hijos carecerían de la vigilancia de sus padres en su educación y cultura", y los pueblos perderían el respeto por las autoridades y se insubordinarían. ${ }^{61}$

En este argumento también cabía la reciente guerra con Estados Unidos y la pérdida de la "mitad del territorio mexicano". Se admiraban los vecinos de Tala, Jalisco, sobre la posible colonización por estadounidenses: "Qué no [harían] esos mismos cuando sean colonos y se les conceda el derecho de ciudadanos con opción a todos los destinos públicos!", si cuando los estadounidenses se apoderaron de Texas, los mexicanos que allí vivían quedaron "reducidos a cero, y la nueva raza inmigrada [era] la que [daba] la ley y la que [disfrutaba] la prosperidad y la abundancia", mientras que para México, por razón de la guerra, todo fue pérdida. ${ }^{62}$ Estas afirmaciones formaban parte del miedo que se quería generalizar entre los mexicanos por la posible presencia de no católicos, pues la legislación era clara en indicar las características que debían cumplir los colonos, quiénes no podían serlo, y los lugares que no eran susceptibles de colonización, por ejemplo, las fronteras y las costas.

En la Nueva Granada se indicaba que con falsas promesas provenientes de las juventudes liberales los artesanos estaban siendo engañados. A ellos se les utilizaba como la base del naciente partido liberal, pero por otra parte se les iba a remplazar con

\footnotetext{
${ }^{58}$ Representación que el ayuntamiento y vecindario del mineral de Guachinango 2.

${ }^{59}$ Representación que los vecinos de Autlan 2.

${ }^{60}$ Representación del ayuntamiento y vecindario de la villa de Etzatlán 5.

${ }^{61}$ Representación que han elevado a las augustas cámaras de la nación los vecinos de Orizava 12-13.

${ }^{62}$ Representación que el ayuntamiento y vecindario de Tala hace al Supremo Gobierno de la Unión, contra la tolerancia de cultos (Guadalajara: Imprenta de Rodríguez, 1849) 3-4.
} 
la presencia de artesanos extranjeros, "protestantes herejes". ${ }^{63}$ Esta lectura, contraria a la inmigración, planteaba la inquietud sobre lo que podría pasar con la población nativa, sobre todo la trabajadora, si se le comparaba con la extranjera en cuanto a cualificación. Y tampoco la inmigración de extranjeros vendería bondades morales. A un español, apodado el Errante, se le criticaba porque a pesar de pedir tolerancia religiosa, y "siendo extranjero", insultaba con la "más grande grosería a los hijos del país". Este extranjero era comparado, por su mal vocabulario con "una verdulera". ${ }^{64}$

Con este discurso encontramos la justificación de que los avances técnicos, industriales, científicos e intelectuales, pasaban a un segundo plano o no importaban, siempre y cuando se conservara no solo la unidad religiosa sino también las bases morales que la religión presuntamente suministraba. Así, se prefiguraba lo que fue la discusión de la Iglesia católica contra los avances científicos que podrían negar la existencia de Dios, y también la crítica a la modernidad. Puntualmente, para los casos que estamos estudiando, valdría la pena preguntarse si no era una forma de justificar el atraso en el que se encontraban los países para mediados del siglo XIX, lejos ya de participar de la carrera industrializadora que se había emprendido años atrás en Occidente.

El quinto argumento era de carácter histórico pues mostraba cómo la tolerancia religiosa, y la presencia de extranjeros, habían traído consecuencias negativas. El punto neurálgico aquí era el de la reciente guerra con Estados Unidos en donde México perdió la mitad de su territorio. En una representación se afirmaba que, a pesar de esa experiencia reciente, "lección terrible y humillante", refiriéndose a la guerra con Estados Unidos, a los que tildaban de "codiciosos vecinos del Norte", se había propuesto no fomentar la discordia ni la desunión y, por el contrario, a "soldar los ya rotos vínculos de nuestra fraternidad nacional". Pero no había sido así, pues se cometió el "osado absurdo" de proponer la tolerancia de "religiones falsas", pero no de la manera pasiva como hasta ese momento existía sino como se ejercía la religión católica en el país, es decir "con la erección de templos y altares, con la predicación de doctrinas corrompidas, antisociales y sacrílegas, con prácticas y costumbres repugnantes" ${ }^{65}$ En este sentido parecía que una de las interpretaciones que se tenía sobre la tolerancia religiosa, como la práctica privada del culto religioso de quienes no eran católicos, pudiera ser aceptada pero no pasaba lo mismo con el culto público y la labor misional.

Además de la guerra con Estados Unidos se acudía a lo que podría llamarse un principio reivindicativo de la nacionalidad e identidad mexicanas, las que se consideraban mancilladas desde la llegada de los españoles. Así, la eventual colonización de europeos y norteamericanos era vista como "temible" debido a que aquellos se consideraban superiores, como lo habían hecho los españoles en la Conquista, o como podía verse

\footnotetext{
${ }^{63}$ Un agrícola del vecindario, "Lutero y el catolisismo. Artículo primero" (sic), El clamor de la verdad, (Bogotá) 29 de octubre de 1848, 4. Cortés Guerrero, “Argumentos” 68.

64 “Intolerancia, fanatismo, incivilidad”, El Duende, (Bogotá) 30 de mayo de 1847, IV.

${ }^{65}$ Representación del ayuntamiento y vecindario de la villa de Etzatlán 1-2. En otra representación se llamaba a los estadounidenses "despiadados americanos del Norte". Véase: Representación que los vecinos de Autlan 3.
} 
con los "funestísimos sucesos" de 1838 y 1847, refiriéndose a las recientes guerras contra potencias extranjeras, primero Francia con la guerra de los pasteles y después Estados Unidos. De esta forma, la colonización era vista como el pretexto de los que querían que en México se alzara "altar contra altar", o que se colocara en un mismo altar el "arca santa y el ídolo Dagon". ${ }^{66}$

Solía afirmarse, muchas veces sin rigor histórico, que, en Europa, Alemania, Holanda, Suiza, Francia y Escocia, por solo citar unos ejemplos, "fueron inundadas de sangre", ${ }^{67}$ o se habían "llenado de sangre" ${ }^{68}$ o vertieron "lágrimas, sangre y todo género de desgracias" ${ }^{69}$ por las discordias religiosas. De igual manera, y haciendo alusión directa al proyecto de colonización, se indicaba que aquél traería "los males que [habían] fructificado en otros países". ${ }^{70}$

Paradójicamente en la Nueva Granada, uno de los ejemplos que se mostraba del mal que el protestantismo hacía en donde se presentaba, era México y su reciente experiencia con la invasión estadounidense. Esto se decía debido a que una de las propuestas para atraer inmigrantes a Nueva Granada era la de acoger a los que primero llegaran a Estados Unidos y allí, por diversos motivos, no fueran bien recibidos o no tuvieran oportunidad para quedarse. Ante esta situación, y debido a que en ese momento las tropas estadounidenses aún estaban en México, se afirmaba que una eventual invasión a la Nueva Granada no ocurriría, pues Estados Unidos no se apropiaría de territorios separados por otros países. Esta afirmación se hizo antes de la compra de Alaska por parte de Estados a Rusia en 1867. Además, se afirmaba en la Nueva Granada, que en el caso de la pérdida de Texas fueron los mexicanos los que entregaron ese territorio por la "codicia de algunos de sus gobernantes, por la ambición de otros, por la anarquía general y por la negligencia y falta de valor y de espíritu público de todos". ${ }^{71}$

Siguiendo con el ejemplo mexicano se afirmaba que con menos ejército y recursos la Nueva Granada podría haber detenido un ejército como el que dominó México, y si hubiese entrado en el territorio habría sido hecho prisionero. Para los escritores, la actitud de México era un "descrédito" a la "raza española", por lo que deseaban que en alguna oportunidad Nueva Granada o Venezuela pudiesen hacer reivindicar el "honor" de las repúblicas suramericanas. ${ }^{72}$ En este sentido, la defensa del territorio por la presencia de una fuerza extranjera esencialmente protestante se convertiría en un asunto de orgullo no tanto nacional sino más bien católico.

\footnotetext{
${ }^{66}$ Representación del vecindario de la Magdalena al supremo gobierno nacional, contra la introducción de sectas en México (Guadalajara, Imprenta de Rodríguez, 1848) 3.

${ }^{67}$ Representación del ayuntamiento y vecindario de la villa de Etzatlán 3.

${ }^{68}$ Representación que han elevado a las augustas cámaras 12.

${ }^{69}$ Representación que los vecinos de Autlan 6.

${ }^{70}$ Representación que los vecinos de Autlan 1.

71 "Inmigración”, La Época, (Bogotá) 30 de julio de 1848: III.

72 “Inmigración”, La Época, (Bogotá) 6 de agosto de 1848: III.
} 
El sexto argumento, relacionado con el anterior, indicaba que de ser necesaria la inmigración y colonización por parte de extranjeros debería preferirse a los católicos provenientes de diversos lugares de Europa, o, en su defecto, a los pobres y vagos. En México, el obispo Aranda indicaba que no entendía por qué si recientemente se había perdido la mitad del territorio se aludía a la "[...] inmigración de extranjeros, y de inmigración muy abundante y numerosa, y de tanta que no se [creía serían] suficientes las innumerables familias de católicos que de muchas partes podrían venir". ${ }^{73}$ De no acudirse a los inmigrantes católicos el gobierno mexicano debería actuar como un buen padre que no era feliz por tener muchos hijos sino porque podía mantenerlos. En ese sentido, había muchos mexicanos viviendo en las ciudades que podían ser empleados en los terrenos baldíos, de tal forma que mientras hubiese un solo pobre en México no deberían traerse de otras partes. Ahora bien, si después de distribuir la tierra entre los mexicanos sobraba alguna podría llamarse a católicos de España que vendrían gustosos a un pueblo con el mismo idioma, costumbres y "sangre". ${ }^{74}$ Esta filiación sanguínea los haría simpatizar con los mexicanos y no con los estadounidenses, evitando repetir lo que pasó con los colonos en Texas.

En Nueva Granada, para 1847, se planteó el mismo argumento. En las provincias centrales del país había suficiente población, la que podía ser desplazada a los lugares en donde hacía falta. Además, esa población se caracterizaba por su buena "moralidad", con lo que se destruía el argumento de que la inmigración era necesaria también por ese motivo, el de mejorar la parte moral de la población nativa. ${ }^{75}$

En este sexto argumento puede verse con claridad un ejemplo de xenofilia, es decir, preferencia por lo extranjero, pero porque tiene las mismas características que el referente nacional, en este caso, la religión católica. Es necesario indicar que la filiación católica que definiría la xenofilia trascendía los límites nacionales para relacionarse con el orbe y la ecúmene católicos. Es decir, se prefería al católico por el solo hecho de serlo independientemente de su nacionalidad.

El séptimo argumento hacía referencia a que la tolerancia religiosa y la introducción de religiones diferentes a la católica romperían la unidad que los países habían construido, es decir acudía a la historia y tradición católicas de los pueblos. En México, el citado obispo de Guadalajara, Diego Aranda, afirmaba que era el tiempo de alzar la voz para "hacer valer ante las supremas autoridades de la República y ante la nación entera los solidísimos incontrastables fundamentos de la verdad católica, y la necesidad de profesarla exclusivamente en nuestro país". Según Aranda, la católica era la religión que sacó al pueblo de la barbarie y que reformó sus costumbres. Este era el discurso de la religión como primera base fundamental de la nación, tal como había quedado plasmado en el Plan de Iguala en 1821 y que había sido sancionada en el Acta constitutiva de 1824, en la primera constitución federal en ese mismo año, y en las constituciones particulares de los estados. ${ }^{76}$

\footnotetext{
${ }^{73}$ Aranda, Pastoral 11.

${ }^{74}$ Aranda, Pastoral 11. Argumentos similares pueden verse en Representación del vecindario de la Magdalena 1.

75 "Población", La Gaceta Mercantil, (Santa Marta) 12 de octubre de 1847: 2.

${ }^{76}$ Aranda, Pastoral 6-7.
} 
La unidad católica mostraba la relación indisoluble que debería existir entre el mexicano y el catolicismo, lo que conllevaba a afirmar que el mexicano era también católico. Por ello era inimaginable que hubiese mexicanos que apoyaran la introducción al país de religiones diferentes a la católica. En una representación se indicaba que los que promovían la tolerancia solo tenían de mexicano el nombre, "la casualidad de haber nacido en este desgraciado país", pues el que era católico no podía dejar de serlo salvo que cayera en la incredulidad o la indiferencia. Estos mexicanos parecían más bien "extranjeros" que intentaban culminar la obra comenzada por las armas, pero de forma "menos estrepitosa", refiriéndose a la guerra con Estados Unidos. De esa manera la penetración protestante sería la mejor forma de acabar con la nacionalidad, como sucedía con los estadounidenses a quienes se les estaban brindando las condiciones para quedarse con todo el país y "sin ningún trabajo, ni dificultades". En ese mismo documento se indicaba que los acérrimos liberales, quienes detestaban cualquier herencia española, se sacarían la sangre "goda" que corría por sus venas y la "remplazarían con la muy ilustre de los dignos hijos del Septentrión". Siguiendo con sus argumentos, se indicaba que el protestantismo caducaba y vacilaba por lo que ningún mexicano católico "podía abjurar su creencia” pues esto lo haría "detestable", incluso para los protestantes, quienes sospecharían de ese cambio pues no lo verían como una muestra de cristianismo sino de un "corazón corrompido que [quería] entregarse sin freno a la satisfacción brutal de sus apetitos". ${ }^{77}$ Es decir, según esta lógica, que un católico se convirtiera en protestante haría que los protestantes sospecharan de su integridad.

Siguiendo con lo anterior, los proyectos de colonización y de tolerancia religiosa lo que pretendían era desunir al pueblo mexicano cuando después de la experiencia bélica reciente lo que se requería era la unión contra el enemigo "que supo aprovecharse de nuestra desunión para humillarnos". ${ }^{78}$

Con la propuesta de la ley sobre inmigración de extranjeros a la Nueva Granada también se despertó la idea de que la unidad del país estaba en peligro. Por ello se criticó que se pensara en el arribo de no católicos lo que supondría la llegada de "enjambres de extranjeros" y que además de los "profesores de diferentes sectas" también llegasen "súbditos del emperador de los chinos". La idea era que a ningún extranjero no católico se le permitiría, ni sería "político", permitirle comprar tierras pues eso sería entregarle territorio a potencias extranjeras. ${ }^{79}$ Es decir, la presencia de no católicos generaría problemas de seguridad nacional.

Es importante recalcar que con argumentos como este se reforzaba la idea de que el catolicismo era la cualidad que distinguía a la comunidad nacional. Esto es que la nacionalidad pasaba por la pertenencia a la religión católica. En este sentido ser mexicano y ser neogranadino, posteriormente colombiano, significaba directamente ser católico, resultando una especie de sinonimia. Finalizando el siglo XIX, en ambos

\footnotetext{
${ }^{77}$ Representación que el ayuntamiento y pueblo de Teocuitatlan 1-4.

${ }^{78}$ Representación que el ayuntamiento y vecindario del mineral de Guachinango 2.

79 “Tolerancia religiosa. Artículo primero", El clamor de la verdad, (Bogotá) 23 de enero de 1848: 4.
} 
países, esta relación fue más clara. De igual forma pasaba con la ciudadanía donde se indicaba que el buen ciudadano era el buen católico. La posible presencia de no católicos en ambos países tensionaría esta relación nacionalidad-catolicismo que se creía era natural.

El octavo argumento mostraba a la tolerancia religiosa como promotora del error en contravía de la verdad blandida por el catolicismo. Este argumento indica que el catolicismo había regenerado, de manera positiva, el mundo político, y desarrolló la obediencia al poder civil y a la verdadera ciencia. En cambio, las sectas -refiriéndose a las religiones no católicas- y el protestantismo eran "hijos" del error, "intolerantes", que seducían a los pueblos "verdaderamente incivilizados", apoyados por la "perversidad humana", debido a que se oponían a la única religión verdadera. Con esa actitud conducían al cisma y al deísmo. El protestantismo producía "funestos efectos en los pueblos del globo separados de la comunión romana" ${ }^{80}$ Es decir, el protestantismo no había generado, en donde era mayoritario, las condiciones de prosperidad y felicidad que se le atribuían.

La tolerancia religiosa se relacionaba con otros errores como el indiferentismo en materia de religión, el cual era como "rama del tolerantismo, árbol dañado", que solo producía "malos frutos". Además, porque el indiferentismo permitía que religiones diferentes a la católica, vistas como falsas, intentaran penetrar en la sociedad. De esta forma se calificaba esa indiferencia como "cobardía en defensa de la religión", por lo que era inconcebible no defenderla: “¡Cómo! ¡Viéndola atacada por todas partes, viendo a mil enemigos armados contra ella, declararle una guerra abierta: permaneceríamos neutros entre ella y sus enemigos, sin tomar partido ni por ella, ni contra ella!" ${ }^{81}$

Es importante resaltar cómo para demostrar que los errores del protestantismo ya habían sido desenmascarados se recurría constantemente, en ambos países, al intelectual español Jaime Balmes, que con sus escritos había "pulverizado y deshecho como la niebla tantos sofismas y errores", ${ }^{82}$ a la vez que mostraba el "benéfico influjo de la civilización" católica ${ }^{83}$ En la Nueva Granada se afirmaba que Balmes había destruido los argumentos de Martín Lutero, cantando los triunfos del catolicismo sobre la "tumba fúnebre" del reformador alemán. ${ }^{84}$ Aquí es necesario llamar la atención sobre cómo se han trabajado poco las fuentes intelectuales de las que bebieron los defensores de la intolerancia religiosa, por ejemplo el referenciado Jaime Balmes y ver qué tanto de lo escrito por ese apologista católico fue entendido en su contexto y qué tanto tergiversado en beneficio de los intereses particulares, en este caso de católicos mexicanos y neogranadinos. ${ }^{85}$

\footnotetext{
${ }^{80}$ Exposición del ilustre ayuntamiento y vecinos de Córdova 2.

81 “Indiferencia en materia de religión”, El clamor de la verdad, (Bogotá) 27 de febrero de 1848: 3.

${ }^{82}$ Error capital de los que profesan la tolerancia (Guadalajara: Imprenta de Rodríguez, 1848), 2.

${ }^{83}$ Representación del vecindario de la villa de Mascota 5.

${ }^{84}$ Un agrícola del vecindario, "Lutero y el catolisismo. Artículo primero" (sic), 1; Cortés Guerrero, "Argumentos" 67.

${ }^{85}$ Véase Javier Barraycoa Martínez, "El Balmes apologeta en El protestantismo comparado con el
} 


\section{Conclusiones}

La discusión por la tolerancia religiosa relacionada con la inmigración puede verse como un escenario más en donde religión y política fueron empleadas, casi que indistintamente, por los sectores de la sociedad que estaban configurando proyectos de Estado y sociedad. Ese empleo de religión y política, o política y religión, es característico del siglo XIX en la medida de que ambas son consideradas como componentes esenciales de los imaginarios e ideales de lo que debería ser la sociedad. Y aquí es necesario aclarar que la religión no es el componente de la sociedad tradicional relacionada con el mundo colonial español y que la política no es el componente de un proyecto societario moderno y liberal. Ambas, política y religión, se funden y confunden en los múltiples proyectos y formas de ver el mundo que afloraron a lo largo del siglo XIX. No se pueden entender una sin la otra. En todas las discusiones en donde se ponen sobre la mesa proyectos de Estado, proyectos institucionales y proyectos de sociedad para los países que se estaban formando después de la Independencia, y de sus respectivas sociedades, la política y la religión, esgrimidas, enarboladas, usadas y utilizadas por diversos actores sociales, estaban presentes.

Al comparar dos países que estaban en formación, recientemente independizados de España, pero que en sus primeros años de república han vivido experiencias diferentes (las intervenciones extranjeras que sufrió México son ejemplo de ello), observamos cómo, en esencia, las expectativas y los temores que se presentaban por la tolerancia religiosa y la inmigración de no católicos, eran las mismas. Se vislumbraba el camino de progreso y civilización o se creía que la sociedad estaba en peligro. Pareciera, salvo cuando se acudía a la historia, a casos puntuales, que los discursos podían emplearse indistintamente para uno u otro país.

De manera práctica la tolerancia religiosa y la inmigración en México y la Nueva Granada estaban íntimamente ligadas con la idea de progreso. Así, al promover la inmigración extranjera con la consiguiente colonización solo se le estaba dando un sentido concreto a una discusión que podía abarcar desde la teología, la filosofía y hasta la historia. En este sentido la imagen del protestantismo, y del protestante, estaba vinculada con el desarrollo del capitalismo y con las libertades que le eran inherentes: políticas y económicas. Esto afloró con fuerza a finales de la década de 1840. Debe anotarse que quienes se oponían a la inmigración y colonización por inmigrantes no católicos y a la tolerancia religiosa no estaban en desacuerdo ni con el capitalismo ni con el progreso. Ellos creían que ni el capitalismo ni el progreso debían pasar, necesariamente, por la tolerancia religiosa lo que significaba no solo que no creían que el desarrollo histórico del capitalismo estuviera vinculado con la Reforma protestante, sino que el capitalismo y el progreso tenían una versión dentro del catolicismo la cual no negaba la religión.

catolicismo", Espiritu.142 (Barcelona, 2011): 379-398; Narciso Juanola Soler. "Balmes contra Rousseau", Verbo. 213-214 Madrid (1983): 315-326. 
La relación tolerancia religiosa e inmigración plantea la cuestión sobre lo que es propio y lo que es ajeno, lo que hacía parte de la identidades mexicana y neogranadina y lo que no. Así, a quienes promovían la tolerancia religiosa se les acusaba de querer romper la unidad nacional basada en la religión. A los inmigrantes no católicos se les imaginaba como agentes contaminantes que con su mal ejemplo afectarían a una sociedad que se había formado, supuestamente, con una moral sana, la católica. De esta forma el extranjero era un sujeto que podía llegar a ser peligroso si no tenía como una de sus características, vista como cualidad o virtud, el ser católico. Ahora bien, encontramos la contraparte: quienes veían a los extranjeros como sujetos activos cuya presencia en ambos países sería positiva pues favorecería el progreso material.

La relación tolerancia religiosa e inmigración nos permite ver problemáticas que se encuentran en estructuras temporales más amplias y que son muy complejas. Esas problemáticas están vinculadas con los proyectos de sociedad, Estado y nación que tenían diversos sectores de las sociedades mexicana y neogranadina. Así, finalizando la década de los cuarenta puede verse como un microcosmos que muestra las características profundas de la estructura de la sociedad. Esto debido a las particularidades del debate sobre tolerancia religiosa, inmigración y colonización. Es importante destacar qué características de esa estructura afloraron para compararlas con las que surgieron en debates, anteriores y posteriores, por la tolerancia religiosa en ambos países.

Al revisar la relación entre tolerancia religiosa e inmigración a finales de la década de 1840 queda preguntarse por qué ese ideal fracasó en el resto de la centuria. También preguntarse por qué si los opositores a la tolerancia religiosa creían que la inmigración podía darse si provenía de países católicos europeos, esto no sucedió. Los irlandeses, italianos y polacos migraron, en gran número, pero a Estados Unidos, país esencialmente protestante. El ideal de una identidad católica que motivaría a los inmigrantes no encajaba con la falta de voluntad política y la carencia de recursos económicos para promover el arribo de extranjeros.

También es importante indicar que comparar dos casos específicos, México y Nueva Granada, debe servir como puerta de entrada a un escenario más grande, América Latina. Intuyo, a manera de hipótesis de trabajo, que, en relación a los temas en este artículo tratados, tolerancia religiosa e inmigración, el mundo andino puede decirnos cosas diferentes al Cono Sur. De esta forma podemos indicar, entre otros aspectos, que en donde más miedo hubo por la inmigración, esta fracasó, mientras que en donde los agentes constructores de ese temor, como por ejemplo la Iglesia católica como institución, tuvieron menos peso y presencia, por ejemplo, Uruguay, a la inmigración no se le vio mayor problema en su relación con la tolerancia religiosa. 


\section{Bibliografía}

\section{Fuentes primarias}

\section{Periódicos}

El clamor de la verdad (Bogotá) 1848.

El Duende (Bogotá) 1847.

El Filotémico (Bogotá) 1850.

El Siglo (Bogotá) 1848.

La Época (Bogotá) 1848.

La Gaceta Mercantil (Santa Marta) 1847.

\section{Libros y folletos}

Aranda, Diego. Pastoral del Illmo. Sr. Dr. D. Diego Aranda, dignísimo obispo de Guadalajara a sus diocesanos, contra la introducción de las falsas religiones en el país. Guadalajara: imprenta de Rodríguez, 1848.

Arboleda, Sergio. La república en la América española. Bogotá: Banco Popular, 1974 (1869).

Colección de documentos sobre inmigración de extranjeros, reimpresos de la Gaceta de la Nueva Granada, número 611, del 13 de setiembre de 1847. Bogotá: imprenta de J. A. Cualla, 1847.

Constitución Política de la República de la Nueva Granada. Bogotá: Imprenta del Gobierno, 1843.

Error capital de los que profesan la tolerancia. Guadalajara: Imprenta de Rodríguez, 1848.

Exposición del ilustre ayuntamiento y vecinos de Córdova, contra la tolerancia de cultos. Puebla: Imprenta de J. N. Valle, 1848.

Las Constituciones de México, 1814-1989. México: H. Congreso de la Unión, Comité de Asuntos Editoriales, 1989.

Proyecto de ley sobre matrimonio entre individuos no católicos. Bogotá: Imprenta de José A. Cualla, 1848. 
Proyectos de colonización, presentados por la junta directiva del ramo, al ministerio de relaciones de la República Mexicana en 5 de julio de 1848. México: Imprenta de Vicente García Torres, 1848.

Representación del ayuntamiento y vecindario de la villa de Etzatlán a las augustas Cámaras, contra la tolerancia de cultos. Guadalajara: Imprenta de Rodríguez, 1848.

Representación del vecindario de la Magdalena al supremo gobierno nacional, contra la introducción de sectas en México. Guadalajara, Imprenta de Rodríguez, 1848.

Representación del vecindario de la villa de Mascota, contra la tolerancia de cultos. Guadalajara: Imprenta de Rodríguez, 1848.

Representación que el ayuntamiento y pueblo de Teocuitatlan hace al Excmo. Sr. Presidente de la República para que se oponga a la admisión de tolerancia de cultos. Guadalajara: Imprenta de Manuel Brambilla, 1849.

Representación que el ayuntamiento y vecindario de Tala hace al Supremo Gobierno de la Unión, contra la tolerancia de cultos. Guadalajara: Imprenta de Rodríguez, 1849.

Representación que el ayuntamiento y vecindario del mineral de Guachinango hace al supremo gobierno de la unión contra la tolerancia de cultos. Guadalajara: Imprenta de Rodríguez, 1849.

Representación que hace el Illmo. Sr. vicario capitular y el Cabildo metropolitano al Supremo Gobierno de la Nación contra el proyecto de tolerancia de cultos. México: Imprenta de la Voz de la Religión, 1849.

Representación que han elevado a las augustas cámaras de la nación los vecinos de Orizava, contra el proyecto de introducir en la República la tolerancia de cultos. México: Tipografía de R. Rafael, 1849.

Representación que los habitantes de Puebla elevan al soberano Congreso de la Unión, contrariando los conatos que para establecer la tolerancia religiosa en nuestro pais, aparecen hoy desgraciadamente. Puebla: Imprenta de Juan Nepomuceno del Valle, 1848.

Representación que los vecinos de Autlan dirigen al supremo gobierno nacional contra la tolerancia de cultos en el país. Guadalajara: Imprenta de Rodríguez, 1849. Rocafuerte, Vicente. Ensayo sobre tolerancia religiosa. México: Imprenta de M. Rivera, 1831.

Samper, José María. Apuntamientos para la historia política i social de la Nueva Granada desde 1810, i especialmente de la administración del 7 de marzo. Bogotá: Imprenta del Neo-Granadino, 1853. 
Tolerancia religiosa e inmigración. México y Nueva Granada a finales de la década de 1840

Vergara y Vergara, José Manuel. Cuestión española. Cartas dirigidas al doctor M. Murillo. Bogotá: Imprenta de la Nación, 1859.

\section{Fuentes secundarias}

\section{Libros}

Arboleda Mora, Carlos. Historia del pluralismo religioso en Colombia. Medellín: Universidad Pontificia Bolivariana, 2002.

Arboleda Mora, Carlos. Pluralismo, tolerancia y religión en Colombia. Medellín: Universidad Pontificia Bolivariana, 2011.

Berninger, Dietir. La inmigración en México (1821-1857). México: Sep setentas, 1974.

Caetano, Gerardo. La secularización uruguaya, 1859-1919. Montevideo: Taurus, 1997.

Carballo, Fabio Hernán. La meretriz inmaculada. Discursos anticatólico y antiprotestante en la Colombia decimonónica. Bogotá: Editorial Universidad del Rosario, 2017.

Covo, Jacqueline. Las ideas de la reforma en México 1855-1861. México: Universidad Nacional Autónoma de México, 1983.

Connaughton, Brian. Entre la voz de Dios y el llamado de la patria. Religión, identidad y ciudadanía en México, siglo XIX. México: FCE, UAM-I, 2010.

Cortés Guerrero, José David. La Batalla de los siglos. Estado, Iglesia y religión en Colombia en el siglo XIX. De la Independencia a la Regeneración. Bogotá: Universidad Nacional de Colombia, 2016.

Díaz Patiño, Gabriela. Católicos, liberales y protestantes. El debate por las imágenes religiosas en la formación de una cultura nacional (1848-1908). México: El Colegio de México, 2016.

Dorantes, Alma. Intolerancia religiosa en Jalisco. México: Instituto Nacional de Antropología e Historia, Dirección de Centros Regionales, Centro Regional de Occidente, 1976.

González Navarro, Moisés. Los extranjeros en México y los mexicanos en el extranjero, 1821-1970, Tomo I. México: El Colegio de México, 1993.

González, Fernán. Poderes enfrentados. Iglesia y Estado en Colombia. Bogotá: Cinep, 1997. 
Locke, John. Ensayo y carta sobre la tolerancia. Madrid: Alianza, 2011.

Luna Argudín, María (coord..). México. La construcción nacional (1830-1880). México: Taurus, Fundación MAPFRE, 2012.

Martínez Silva, Carlos. James Thomson. Un escocés distribuidor de la Biblia en México, 1827-1830. México: Maná, Museo de la Biblia, 2013.

Moreno Palacios, Pablo. Por momentos hacia atrás... por momentos hacia adelante. Una historia del protestantismo en Colombia, 1825-1945. Cali: Universidad San Buenaventura, 2010.

Pani, Erika. Para pertenecer a la gran familia mexicana: procesos de naturalización en el siglo XIX. México: El Colegio de México, 2015.

Uribe, María Teresa y Álvarez, Jesús María. Poderes y regiones: problemas en la constitución de la nación colombiana. 1810-1850. Medellín: Universidad de Antioquia, 1997.

Villegas Revueltas, Silvestre. El liberalismo moderado en México, 1852-1864. México: UNAM, 1997.

\section{Capítulos de libros}

Bastian, Jean-Pierre. "Leyes de Reforma, ritmos de secularización y modernidad religiosa en México, siglo XIX". Las leyes de Reforma y el Estado laico. Importancia histórica y validez contemporánea. Coord. Roberto Blancarte. México: El Colegio de México, 2013.

Bastian, Jean-Pierre. "Tolerancia religiosa y libertad de culto en México, una perspectiva histórica”. Cuadernos del Instituto de Investigaciones Jurídicas. Derecho fundamental de libertad religiosa. México: UNAM, 1994.

Connaughton, Brian. “1856-1857: conciencia religiosa y controversia ciudadana. La conciencia como poder político en un "pueblo eminentemente católico"'. Prácticas populares, cultura politica y poder en México, Siglo XIX. Coord. Brian Connaughton. México: UAM-I/Juan Pablos, 2008.

Connaughton, Brian. "The Enemy Within: Catholics and Liberalism in Independent Mexico, 1821-1860". The Divine Charter. Constitutionalism and Liberalism in Nineteenth Century. Ed. Jaime Rodríguez. Lanham: Rowman and Littlefield Publishers, 2006.

Cortés Guerrero, José David. "Lectura comparada de una época de reformas liberales. México y Colombia a mediados del siglo XIX”. Las Leyes de Reforma y el Estado 
laico: importancia histórica y validez contemporánea. Coord. Roberto Blancarte. México: UNAM, El Colegio de México, 2013.

Lira, Andrés y Staples, Anne. "Del desastre a la reconstrucción republicana, 18481876”. Nueva Historia General de México. México: El Colegio de México, 2010.

Moreno, Pablo. "Presencia protestante en el nacimiento de la república colombiana: el caso de la Sociedad Bíblica Colombiana, 1825". Ecos del Bicentenario. El protestantismo y las nuevas repúblicas latinoamericanas. Ed. Carlos Mondragón. Buenos Aires: Ediciones Kairos, 2011.

Rodríguez, Javier. "Primeros intentos de establecimiento del protestantismo en Colombia”. Historia del cristianismo en Colombia. Dir. Ana María Bidegain. Bogotá: Taurus, 2004.

Roselló Soberón, Estela. "Catolicismo versus protestantismo en los intentos de 'reencantar' el mundo: la patria católica frente a la amenaza de la tolerancia religiosa. México, 1848". Itinerarios e intercambios en la historia intelectual de México. Comps. Miruna Achim y Aimer Granados. México: CONACULTA, UAM-C, 2011.

Santillán, Gustavo. "La secularización de las creencias: discusiones sobre la tolerancia religiosa en México". Estado, Iglesia y sociedad en México, siglo XIX. Coords. Álvaro Matute, Evelia Trejo, y otros. México: Miguel Ángel Porrúa, UNAM, 1995.

Serrano Ortega, José Antonio y Vázquez, Josefina Zoraida. "El nuevo orden, 18211848”. Nueva Historia General de México. México: El Colegio de México, 2010.

Téllez Aguilar, Abraham. "Protestantismo y política en México en el siglo XIX". El protestantismo en México (1850-1940). La iglesia metodista episcopal. Coords. Laura Espejel López y Rubén Ruiz Guerra. México: INAH, 1995.

Vázquez, Josefina Zoraida. “Colonización y pérdida de territorio, 1819, 1857”. El poblamiento de México, Tomo 3, México en el siglo XIX. México: Secretaría de Gobernación, 1993.

\section{Artículos de revistas}

Alanís Enciso, Fernando. "Los extranjeros en México, la inmigración y el gobierno: ¿tolerancia o intolerancia religiosa?, 1821-1830”. Historia Mexicana 45.3 (1996): 539-566.

Barraycoa Martínez, Javier. "El Balmes apologeta en El protestantismo comparado con el catolicismo". Espíritu. 142 (2011): 379-398.

Berninger, Dietir. "Immigration and religious toleration: a Mexican dilemma 18211860”. The Americas 32.4 (abr., 1976): 549-565. 
Burden, David K. "Reform Before La Reforma: Liberals, Conservatives and the Debate over Immigration, 1846-1855". Mexican Studies/ Estudios Mexicanos 23.2 (2007): 283-316.

Castillo Troncoso, Alberto del. "El debate en torno a la tolerancia de cultos en México durante la coyuntura de la posguerra (1848-1849)". Historia y Grafía.14 (2000): 17-34.

Cortés Guerrero, José David. “Argumentos por la tolerancia religiosa en Colombia, 1832-1853”. Historia y Sociedad.33 (julio-diciembre, 2017): 45-76.

Cortés Guerrero, José David. "La Escuela Nacional Preparatoria de México y la Universidad Nacional de los Estados Unidos de Colombia: Lectura comparada de dos proyectos educativos modernizadores; 1867-1878". Anuario Colombiano de Historia Social y de la Cultura.34 (2007): 323-383.

Cortés Guerrero, José David. "Las costumbres y los tipos como interpretaciones de la historia: Los mexicanos pintados por sí mismos y el Museo de cuadros de costumbres". Estudios de Literatura Colombiana.33 (2013): 13-36.

Cortés Guerrero, José David. ““Viva la religión y mueran sus enemigos”: oposición a la tolerancia religiosa en México a mediados del siglo XIX". Anuario Colombiano de Historia Social y de la Cultura.33 (2006): 209-246.

Coy Sierra, Andrey. "Tolerancia religiosa en Bogotá entre 1849 y 1854". Historia Crítica.33 (2007): 74-97.

García Jordán, Pilar. "Reflexiones sobre el darwinismo social. Inmigración y colonización, mitos de los grupos modernizadores peruanos (1821-1919)”. Bulletin Institut Francaise d'études andines 21.2 (1992): 961-975.

Juanola Soler, Narciso. "Balmes contra Rousseau”. Verbo.213-214 (1983): 315-326.

Krauze, Enrique. "Debates históricos sobre la tolerancia". Letras Libres.142 (2010): 18-23.

Martínez Albesa, Emilio. "El primer debate sobre tolerancia religiosa en el México independiente, 1823-1824". Alpha Omega 9.3 (2006): 475-506.

Martínez, Frédérick. “Apogeo y decadencia del ideal de la inmigración europea en Colombia, siglo XIX”. Boletín Cultural y Bibliográfico 34.44 (1997): 3-45.

Santillán, Gustavo. “Tolerancia religiosa y moralidad pública, 1821-1831”. Signos históricos.7 (enero-junio, 2002): 87-104.

Trejo, Evelia. "La introducción del protestantismo en México: aspectos diplomáticos". Estudios de Historia Moderna y Contemporánea de México IX (1988): 149-181. 
Tolerancia religiosa e inmigración. México y Nueva Granada a finales de la década de 1840

\section{Tesis, ponencias, documentos y otros Inéditos}

Coy Sierra, Andrey. Tolerancia religiosa en Bogotá y la revolución liberal de medio siglo (1849-1854). Monografía de pregrado en Historia, Universidad Nacional de Colombia, 2004.

Santillán, Gustavo. Discusiones sobre la tolerancia religiosa en México. 1821-1827. Tesis de Licenciatura en Historia, UNAM, 1997.

Santillán, Gustavo. La tolerancia religiosa en México, 1833-1849. Tesis de Maestría en Historia, UAM, 2000.

Téllez Aguilar, Abraham. Proceso de introducción del protestantismo en México desde la Independencia hasta 1884. Monografía de licenciatura, UNAM, 1989.

\section{Publicaciones en Internet}

http://web.frl.es/DA.html (2017). 